Stereochemistry Research Group of the Hungarian Academy of Sciences

Institute of Pharmaceutical Chemistry

University of Szeged

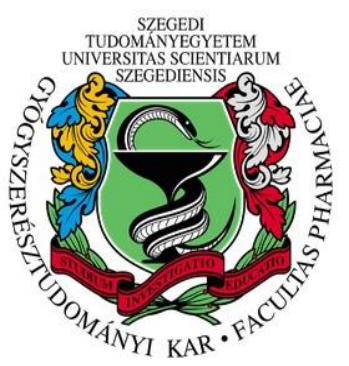

Ph.D. Thesis

\title{
Asymmetric cascade reaction of 2-nitrophenylpyruvates over chirally modified platinum catalyst
}

by

\section{Lenke Kovács}

Supervisors:

Dr. György Szőllősi

Prof. Dr. Ferenc Fülöp

Szeged 


\section{CONTENTS}

List of publications and lectures

Papers related to the thesis, other papers

Scientific lectures related to the thesis, other scientific lectures

1. INTRODUCTION AND AIMS 4

2. LITERATURE SURVEY 6

$\begin{array}{ll}\text { 2.1. Asymmetric catalytic synthesis of chiral hydroquinolines } & 6\end{array}$

2.2. Heterogeneous catalytic preparation of hydroquinolines 8

2.3. Heterogeneous enantioselective hydrogenations 10

2.4. Heterogeneous catalytic reduction of aromatic nitro compounds 13

$\begin{array}{ll}\text { 2.5. Asymmetric hydrogenation in continuous-flow systems } & 16\end{array}$

$\begin{array}{ll}\text { 2.6. Heterogeneous asymmetric cascade reactions } & 18\end{array}$

3. EXPERIMENTAL 21

$\begin{array}{lll}3.1 & \text { Materials and methods } & 21\end{array}$

$\begin{array}{lll}3.2 & \text { Preparation of 2-nitrophenylpyruvic acid esters } & 21\end{array}$

$3.3 \quad$ Typical procedure of the asymmetric catalytic cascade reaction 22

$\begin{array}{lll}3.4 & \text { Hydrogenation procedure in flow system } & 24\end{array}$

4. RESULT AND DISCUSSION 25

4.1. Hydrogenation of 2-nitrophenylpyruvates in batch reactor 25

4.1.1 Solvent effect 26

4.1.2 Influence of the $\mathrm{AcOH}$ and catalyst amount $\quad 27$

4.1.3. Effect of the catalyst support 29

4.1.4 Influence of the $\mathrm{H}_{2}$ pressure $\quad 30$

4.1.5 Effect of the modifier structure and concentration 31

4.1.6 Effect of the substrate concentration and structure $\quad 34$

4.1.7 Reaction pathways in the asymmetric heterogeneous catalytic cascade $\quad 37$

4.2. Hydrogenation of 2-nitrophenylpyruvates in continuous flow system 39

4.2.1 Effect of reaction conditions $\quad 39$

4.2.2 Reactions over catalyst pre-modified by cinchonidine $\quad 41$

5. SUMMARY 45

Acknowledgments $\quad 47$

References $\quad 48$

$\begin{array}{ll}\text { Appendix } & 51\end{array}$ 


\section{List of publications and lectures}

\section{Papers related to the thesis}

I. György Szőllősi, Zsolt Makra, Lenke Kovács, Ferenc Fülöp, Mihály Bartók Preparation of optically enriched 3-hydroxy-3,4-dihydroquinolin-2(1H)-ones by heterogeneous catalytic cascade reaction over supported platinum catalyst Advanced Synthesis \& Catalysis 2013, 355, 1623-1629

IF: 5.542

II. György Szőllősi, Lenke Kovács, Zsolt Makra

Three consecutive steps over the chirally modified Pt surface: asymmetric catalytic cascade reaction of 2 nitrophenylpyruvates

Catalysis Science \& Technology 2015, 5, 697-704

III. Lenke Kovács, György Szöllösi, Ferenc Fülöp

Pt-cinchonidine catalysed asymmetric catalytic cascade reaction of 2nitrophenylpyruvates in flow system

Journal of Flow Chemistry 2015, 5(4), 210-215

IF: 1.878

\section{Other paper}

IV. András Gurka, Imre Bucsi, Lenke Kovács György Szőllősi, Mihály Bartók

Reversal of the enantioselectivity in aldol addition over immobilized di- and tripeptides: studies under continuous flow conditions

RSC Advances 2014, 4, 61611-61618

\section{Scientific lectures related to the thesis}

V. Kovács Lenke, Szőllősi György

Tetrahidrokinolon származékok enantioszelektív előállítása heterogén katalitikus reakcióval

TDK kémia II. szekció

Szeged, Hungary, 26 April 2012.

VI. Kovács Lenke, Szőllősi György

Tetrahidrokinolon származékok enantioszelektív előállítása heterogén katalitikus reakcióval

A Szegedi Ifjú Szerves Kémikusok Támogatásáért Alapítvány 12. Tudományos Elöadóülése

Szeged, Hungary, 8 May 2012.

VII. Kovács Lenke, Szőllősi György

Tetrahidrokinolon származékok enantioszelektív előállítása heterogén katalitikus reakcióval

XXX: Országos Tudományos Diákköri Konferencia, Kémia és Vegyipari szekció Eger, Hungary, 4-6 April 2013. 
VIII. Szőllősi György, Makra Zsolt, Kovács Lenke, Bartók Mihály

Heterogén katalitikus kaszkád reakció királis hidrokinolin származékok enantioszelektív előállítására

Vegyészkonferencia

Hajdúszoboszló, Hungary, 26-28 July 2013.

IX. György Szőllősi, Zsolt Makra, Lenke Kovács, Ferenc Fülöp, Mihály Bartók

Heterogeneous asymmetric catalytic cascade reaction for the preparation of 3-hydroxy3,4-dihydroquinolin-2(1H)-ones

11th European Congress on Catalysis - EuropaCat-XI,

Lyon, France, 1-6 September 2013.

X. Kovács Lenke, Szőllősi György, Fülöp Ferenc

2-nitrofenilpiroszőlősav észterek reakciója cinkonidinnel módosított Pt katalizátoron átáramlásos rendszerben

MKE 2. Nemzeti Konferencia

Hajdúszoboszló, Hungary, 31 August - 2 September 2015.

XI. Kovács Lenke, Szőllősi György, Fülöp Ferenc

2-Nitrofenilpiroszőlősav-etilészter származékok aszimmetrikus kaszkád reakciója

királisan módosított platina katalizátoron

Katalizis Munkabizottsági Ülés

Szeged, Hungary, 11 December 2015.

\section{Other scientific lecture}

XII. György Szőllősi, Lenke Kovács

Cinchona alkaloid catalysts in the asymmetric Michael-addition of fluorinated Cnucleophile to $\beta$-nitrostyrene

Chirality 2014 (26th International Symposium on Chiral Discrimination)

Prague, Czech Republic, 27-30 July 2014. 


\section{INTRODUCTION AND AIMS}

Nowadays, the demand for the production of optically pure enantiomers is continuously growing. Optically pure partially saturated quinoline derivatives are intermediates in the preparation of natural products and pharmaceuticals. The asymmetric catalytic methods developed for preparing chiral hydroquinolines are based on enantioselective catalytic hydrogenations of quinoline derivatives or assembly of the chiral heterocyclic ring using enantioselective catalytic cyclization.

Sustainable and environmentally benign technologies required nowadays in the production of chiral fine chemicals tend to apply heterogeneous catalytic systems, due to the inherent practical advantages connected with separation, reuse, and stability of the catalyst and the opportunity of continuous process operation. Detailed examination of these systems is in the forefront of chemical research. Possibilities to obtain heterogeneous chiral catalysts are the immobilization of homogeneous catalysts and the chirality transfer to the surface of known and active heterogeneous metal particles. Although Pt catalysts modified by cinchona alkaloids were found to be remarkably efficient in the enantioselective hydrogenation of activated ketones, these catalysts are not appropriate for the enantioselective hydrogenation of N-heterocyclic compounds.

A cascade reaction, also known as domino reaction or tandem reaction, is a chemical process in which at least two consecutive steps occur, therefore incorporate multiple bondforming events carried out in one-pot manner. Furthermore, in cascade reactions, isolation of intermediates is not required, as each reaction composing the sequence occurs spontaneously. In spite of their numerous advantages, asymmetric catalytic cascade reactions over heterogeneous chiral catalysts were scarcely reported and only few reactions are known in which the stereoselective step occurs on the solid catalyst surface.

Combination of hydrogenation and continuous-flow technology could be widely used in the pharmaceutical industry for the synthesis of bioactive molecules. Huge advantage of flow systems is the opportunity of the reagent mixture recycling. Due to the fixed catalyst bed, the reaction mixture is separated from the catalyst instantaneously, unlike during batch production. Due to its advantageous characteristics flow chemistry became preferred for industrial application even in fine chemical synthesis. A current trend in the synthetic organic chemistry is the use of continuous-flow processes, which can be performed most advantageously by using modern immobilized reagents or catalysts. 
More than a decade ago it was reported the formation of 3-hydroxy-3,4dihydroquinolin-2(1H)-ones as side products of the Reissert indole synthesis, if the reduction step was carried out with gaseous $\mathrm{H}_{2}$ over $\mathrm{PtO}_{2}$ catalyst. It was highlighted in the above report that during the reaction under reducing conditions, the hydrogenation of the keto group and the reduction of the nitro group are competing reactions and both are catalysed on the $\mathrm{Pt}$ surface, therefore the rate of these two steps determine the ratio of the two main products, i.e. the hydroquinoline and the indole derivatives. Thus, the reaction over Pt catalysts could be used for the enantioselective preparation of valuable hydroquinolines using a heterogeneous catalytic system if the step in which the chiral centre is formed could be made enantioselective.

Inspired by these previous findings obtained over $\mathrm{PtO}_{2}$ catalyst, we have developed the transformation of 2-nitrophenylpyruvates to 3-hydroxy-3,4-dihydroquinolin-2(1H)-one derivatives by an asymmetric cascade reaction over supported Pt catalyst modified by cinchona alkaloids in the presence of $\mathrm{H}_{2}$. We thought that it deserves to study the effect of the reaction conditions on the rates of the two key competitive steps. As heterogeneous catalysts are suitable for use in continuous processes, we also examined the reaction in continuous-flow system using a fixed-bed reactor, in order to test whether these compounds may be efficiently and enantioselectively hydrogenated in a continuously operated experimental set-up. Thus, our aim was to develop a novel asymmetric heterogeneous catalytic cascade reaction, which may be used for the efficient, environmentally benign and sustainable preparation of valuable $\mathrm{N}$-heterocyclic chiral building blocks, with possible application for the preparation of pharmaceuticals. 


\section{LITERATURE SURVEY}

Optically pure N-heterocyclics and their substituted derivatives are essential pharmaceuticals or chiral building blocks used in the preparation of biologically active compounds [1,2]. Chiral quinoline derivatives such as hydroquinolines have increased importance in the preparation of a range of drug candidates applied for curing Parkinson's disease [3] or schizophrenia [4] (Figure 1). Various methods are available for the preparation of the quinoline moiety [5,6]. Traditionally, optically pure quinoline including hydroquinoline derivatives needed in the pharmaceutical industry were either prepared by resolution of racemic mixtures [7] or by asymmetric synthesis using chiral materials as substrates or auxiliaries [8]. Recent trends of decreasing the environmental impact of the processes used for the preparation of fine chemicals motivated the development of asymmetric catalytic methods for the preparation of high added value chiral building blocks used in the pharmaceutical industry. Moreover, developing environmentally benign and long term sustainable processes requires the application of reusable, highly active and selective, long life heterogeneous catalytic systems [9-11]. Accordingly, the development of such catalytic systems for the preparation of chiral hydroquinoline derivatives may accelerate the investigation and application of pharmaceuticals bearing this heterocyclic moiety.<smiles>[R1]NC(=O)Nc1cccc2c1CC(O)C(=O)N2[R]</smiles>

anti-inflammatory agents<smiles>[R]c1cccc(-c2ccc3c(c2)CC(O)C(=O)N3[R])c1</smiles>

drugs to treat cancer<smiles>[R]C=C1C(=O)C(N)Cc2ccccc21</smiles>

against schizophrenia<smiles>CN[C@H]1Cc2cccc3[nH]c(=O)n(c23)C1</smiles>

potential antiparkinson drug

Figure 1. Chiral drugs containing hydroquinoline moieties $[3,4]$.

\subsection{Asymmetric catalytic synthesis of chiral hydroquinolines}

The asymmetric catalytic methods developed for preparing chiral hydroquinolines [12] are based on enantioselective catalytic hydrogenations of quinoline derivatives [13-18] or the assembly of the chiral heterocyclic ring using enantioselective catalytic cyclization [19-22].

Following the development of chiral metal complexes highly effective in the enantioselective hydrogenation of a wide range of prochiral compounds [23], the 
enantioselective hydrogenation and transfer hydrogenation of quinolines become frequently applied for the preparation of optically pure hydroquinolines (Scheme 1) [24,25]. However, during the last fifteen years catalysis by optically pure organic compounds so-called „organocatalysts" also proved to be efficient for preparing chiral compounds [26,27]. These catalysts are convenient alternatives of chiral metal complexes, due to their lower costs, their availability from natural sources, less difficulties in their use as compared with the sensitive complexes and due to avoiding the possible contamination of the products with metal traces. Accordingly, efficient organocatalysts were developed for use to catalyse many organic reactions in which chiral products are formed. Moreover, these catalysts tolerate the presence of other catalytically active species in the system, which make them suitable for applications in reactions in which several transformations are carried out consecutively in one-pot manner, such as domino or cascade reactions [28,29].
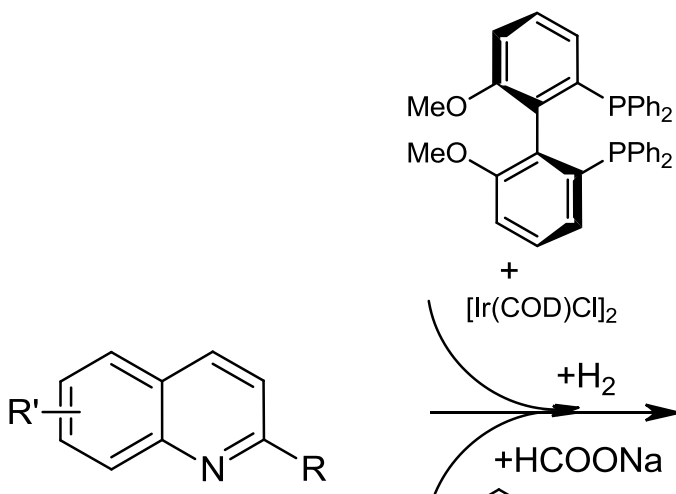

$+$

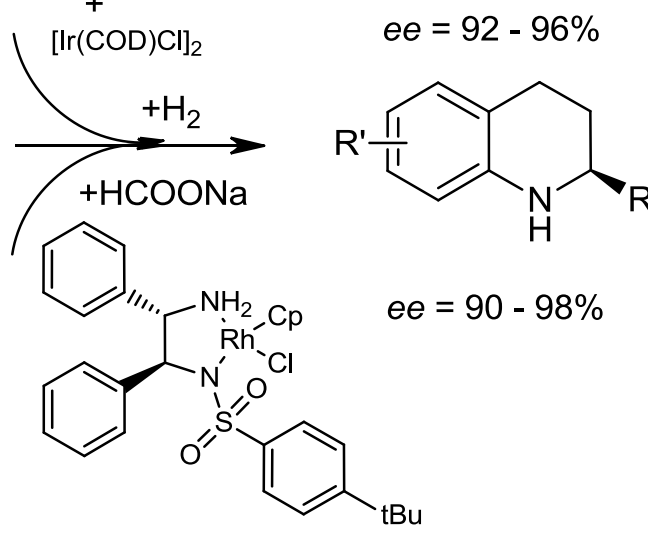

Cp: Pentamethylcyclopentadiene

Scheme 1. Enantioselective synthesis of tetrahydroquinolines by hydrogenation or transfer hydrogenation (ee: enantiomeric excess) [24,25].

According to the modern trends of today's organic synthetic chemistry, several organocatalyzed asymmetric reactions have been developed for the preparation of chiral hydroquinoline derivatives affording good yields and excellent enantioselectivities [19,30]. An outstanding example is the domino reaction catalysed by a chiral pyrrolidine derivative easily prepared from L-proline, which is consisted of an initial enantioselective heteroMichael addition followed by an aldol condensation (Scheme 2) [19]. 
<smiles>[R]C=CC=O</smiles><smiles>C=CC=O</smiles><smiles>[R]C1Nc2ccccc2C=C1C=O</smiles>

ee $=94-98 \%$

Scheme 2. Enantioselective synthesis of dihydroquinoline derivatives by organocatalyzed domino reaction [19].

\subsection{Heterogeneous catalytic preparation of hydroquinolines}

Sustainable and environmentally benign technologies required nowadays in the production of chiral fine chemicals tend to apply heterogeneous catalytic systems, due to their multiple advantages as compared with the homogeneous catalytic methods, among which the reuse of the catalyst or its application in flow systems are very significant from economic point of view [11,31]. Besides homogeneous complexes found efficient in the hydrogenation of quinoline derivatives, the use of heterogeneous, skeletal or supported transition metal catalysts were also applied for preparing hydroquinolines from quinoline derivatives [32].

More than a decade ago in the reaction of 2-nitrophenylpyruvates over $\mathrm{PtO}_{2}$ heterogeneous catalysts in $\mathrm{H}_{2}$ atmosphere the formation of 3-hydroxy-3,4-dihydroquinolin2(1H)-ones was observed by Murakami and co-workers [33]. The transformation of 2nitrophenylpyruvates using $\mathrm{Zn}+$ acetic acid or even heterogeneous $\mathrm{Pd}+\mathrm{H}_{2}$ leads to the formation of indole derivatives as reported by Reissert [34].<smiles>[R][R]1ccc(CC(=O)C(=O)OCC)c([N+](=O)[O-])c1</smiles>

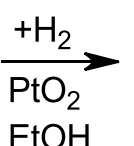
$\mathrm{EtOH}$<smiles>O=C1Nc2cc[c]cc2CC1O</smiles>

major product<smiles>CCOC(=O)C1=Cc2cc[R]([nH]2)C=C1</smiles>

Scheme 3. Products formed from 2-nitrophenylpyruvates over $\mathrm{PtO}_{2}$ catalyst in the presence of $\mathrm{H}_{2}$ [33].

Accordingly, the reaction over Pt catalysts may be used for the enantioselective preparation of valuable hydroquinolines using a heterogeneous catalytic system if the step in which the chiral centre is formed could be carried out enantioselectively. The authors of the 
above research highlighted that during the reaction under reducing conditions, the hydrogenation of the keto group and the reduction of the nitro group are competing reactions and both are catalysed on the Pt surface, therefore the rate of these two steps determine the ratio of the two main products, i.e. the hydroquinoline and the indole derivatives. The reaction pathways according to which these products are formed are illustrated on Scheme 4. If the first step is the reduction of the nitro group, the condensation of the formed amino and the keto group will lead to the usual indole derivative. However, if the hydrogenation of the $\alpha$ keto group occurs initially, the amino group formed by the consequent reduction of the nitro group may and will react with the ester moiety forming the racemic hydroxyquinolone derivative by intramolecular amidation [33].

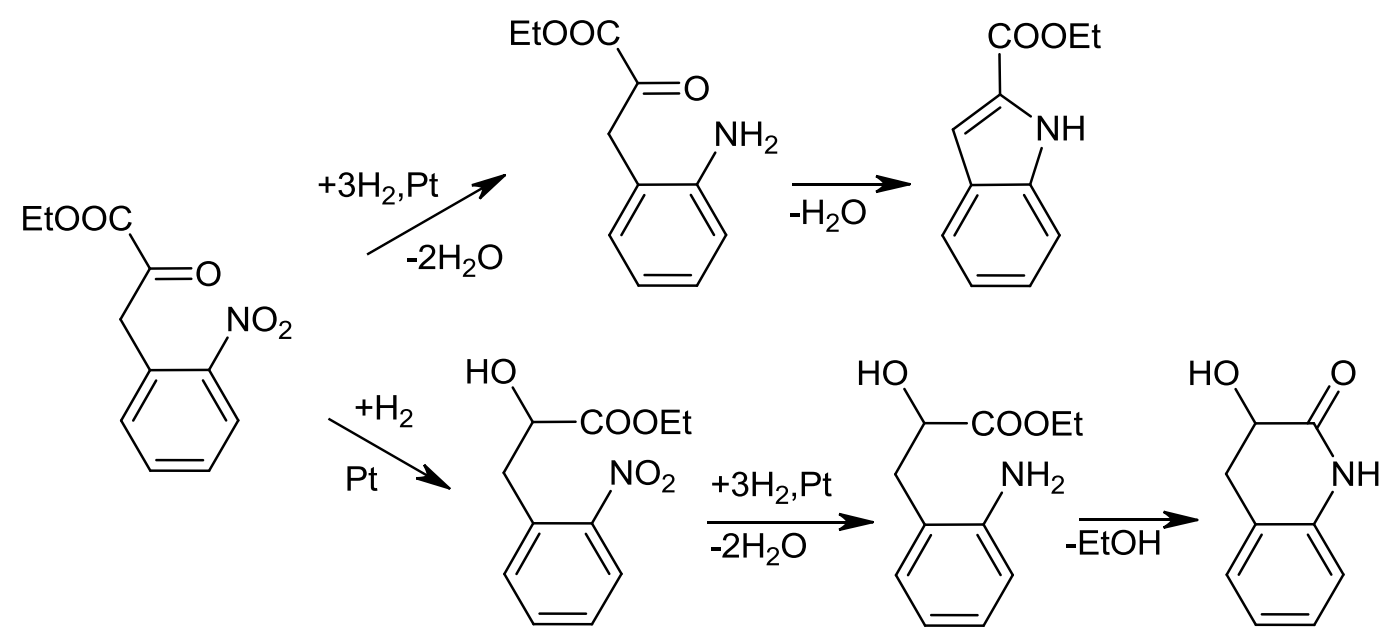

Scheme 4. Reaction pathways leading to indole or hydroquinoline derivatives [33].

According to these pathways the fast and enantioselective hydrogenation of the $\alpha$-keto ester moiety may assure the preparation of the optically enriched hydroquinolone products by this heterogeneous catalytic cascade reaction. Thus, we aimed the development of a heterogeneous asymmetric catalytic system for the production of enantio-enriched hydroquinoline derivatives by the above cascade reaction of 2-nirtophenyl pyruvates. As the two key competitive steps of the reaction are the enantioselective hydrogenation of the activated keto group and the reduction of the nitro group, results obtained so far on the enantioselective heterogeneous catalytic hydrogenations and the heterogeneous catalytic reduction of the nitroaromatics will be shortly overviewed in the followings.

\subsection{Heterogeneous enantioselective hydrogenations}


The area of catalytic hydrogenation continues to develop fast, due to its wide application in organic synthesis [32]. Moreover, the asymmetric hydrogenation of prochiral unsaturated compounds, such as alkenes, ketones, and ketimines, is one of the most efficient methods for the preparation of optically active compounds. Since 1968, when the groups of Knowles and Horner published independently pioneering examples of asymmetric hydrogenations using chiral metal complexes as catalysts [35], homogeneous enantioselective hydrogenations become a widely applied method for the preparation of optically pure compounds. The development of various metal complexes for industrially relevant applications such as Ru complexes with BINAP (2,2'-bis(diphenylphosphino)-1,1'-binaphthyl) or Ts-DPEN (N-p-tosyl-1,2-diphenylethylenediamine) complexes reported by Noyori and coworkers demonstrated the versatility of the homogeneous catalytic hydrogenations and transfer hydrogenations [36]. The outstanding results obtained in the asymmetric catalytic hydrogenations were recognized even by awarding Noble prize in chemistry in 2001 to Knowles and Noyori [35,36].

Due to the inherent practical advantages of the heterogeneous catalytic systems connected with separation, reuse, and stability of the catalyst and the opportunity of continuous operation [9-11], detailed examination of these systems is in the forefront of chemical research. The development of enantioselective heterogeneous catalysts for asymmetric hydrogenations was among the earliest attempt of researchers working on catalytic transformations. Immobilization of chiral metal complexes over solid supports by various methodologies proved to be a viable method for obtaining heterogeneous catalysts, however, the obtained catalysts often couldn't reproduce the efficiency of the soluble metal complexes. Although, few examples are known of highly efficient immobilized chiral metal complexes [37], their laborious preparation by few additional steps make them less favoured in the preparative laboratory routine. Moreover, some of the disadvantages of using metal complexes, such as their high costs, difficult handling and metal leaching were also kept.

Another approach to obtain heterogeneous chiral catalysts for enantioselective hydrogenations is the chirality transfer to the surface of catalytically active heterogeneous metal particles. Early attempts by Akahori reported the asymmetric hydrogenation of azalactones in the presence of heterogeneous catalyst made of palladium deposited on silk (Scheme 5) [38]. However, by far the most important class of enantioselective heterogeneous catalysts were obtained by surface modification of metallic catalysts using chiral natural compounds, so-called modifiers. The chiral modifiers which induce enantio-differentiation 
during the reaction by interaction with the substrate can be fixed on the surface of the active metals through simple adsorption.

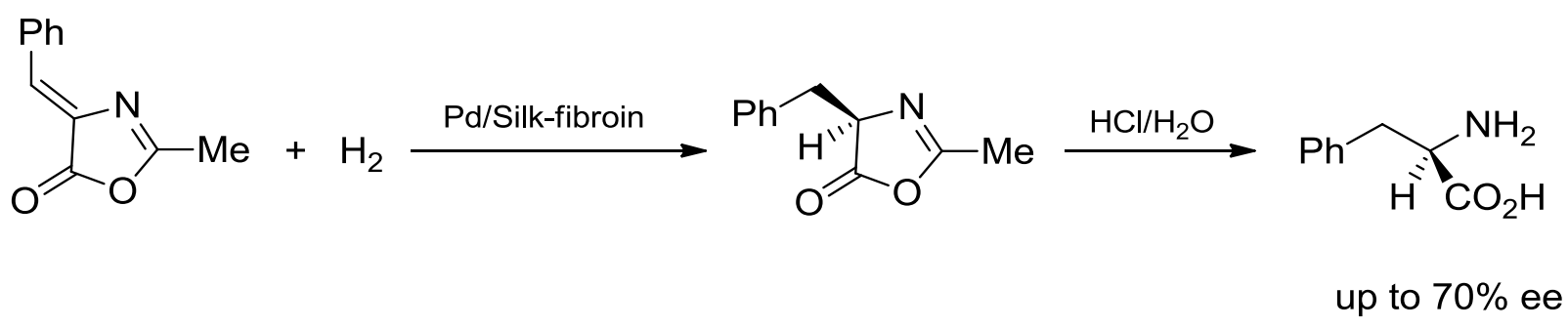

Scheme 5. Asymmetric hydrogenation of an azalactone catalysed by silk-fibroin-supported palladium.

Historically the optically pure tartaric acid modified Ni catalysts were the first chirally modified heterogeneous catalysts described, which following extensive studies and optimization of the reaction conditions, catalyst preparation method and the substrate structure, permitted the highly selective preparation of optically enriched products through hydrogenation of $\beta$-keto esters, $\beta$-diketones and later that of simple aliphatic prochiral methyl ketones, too (Scheme 6) [39-41].

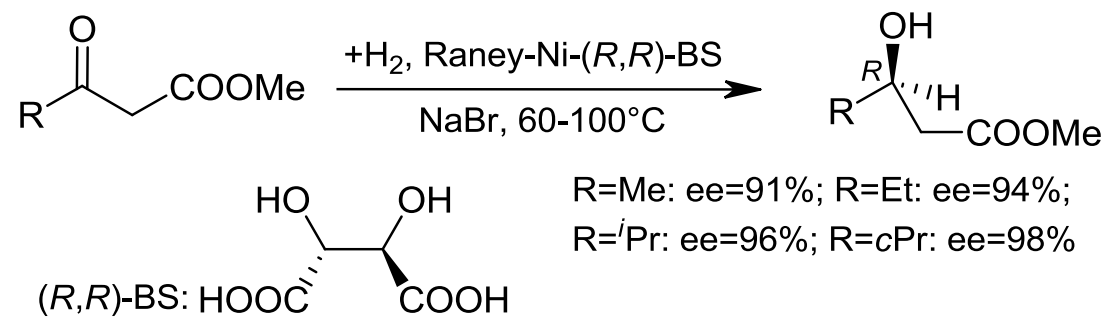

Scheme 6. Enantioselective hydrogenation of $\beta$-keto esters over tartaric acid-modified Ni catalyst $[40,41]$.

Similarly, Pt catalysts modified by cinchona alkaloids have been successfully applied for the enantioselective hydrogenation of several activated ketones, such as $\alpha$-ketoesters, $\alpha$ ketoacids, $\alpha$-ketoamides, $\alpha$-diketones, $\alpha$-keto acetals, $\alpha$-ketoethers, trifluoromethyl ketones, ketopantolactone, and others [42-45]. However, most of the knowledge about this catalytic system has been collected using the enantioselective hydrogenation of methyl or ethyl pyruvate and benzoate, originally reported by Orito and co-workers (Scheme 7) [46,47]. The chiral modification was carried out by simply adding cinchona alkaloids to the catalyst or even better, to the reaction mixture. As in the case of the enantioselective hydrogenation on Ni catalysts, a variety of factors influenced the enantioselectivity, including: temperature, the properties of the solvent, modifier concentration, and the size of the Pt particles $[44,45]$. The 
knowledge gathered since the discovery of this catalytic system has been covered in various reviews, whereas detailed investigations led to over $90 \%$ ee obtained in the hydrogenations of a variety of $\alpha$-keto esters and to significantly extended scope of the reaction.

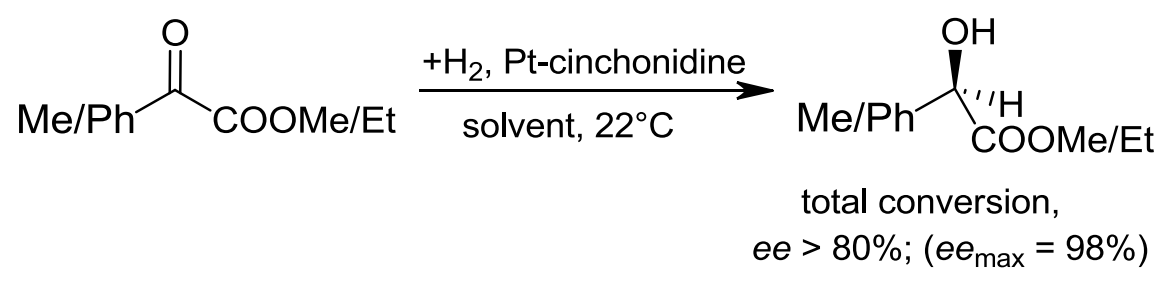

Scheme 7. Enantioselective hydrogenation of $\alpha$-keto esters [42-47].

After discovery of the chiral Pt catalysts modified by cinchona alkaloids it was shown that these modifiers may induce enantioselectivity also in the hydrogenation of unsaturated acids over Pd catalysts [48]. Cinchonidine-modified Pd proved to be the most effective catalyst for enantioselective hydrogenations of prochiral $\mathrm{C}=\mathrm{C}$ groups in $\alpha, \beta$-unsaturated carboxylic acids, studied extensively by Nitta and co-workers and later by our research group [49-51]. High enantioselectivities were obtained in the hydrogenation of $\alpha$-phenylcinnamic acid and its various substituted derivatives (Scheme 8), whereas, the hydrogenation of aliphatic unsaturated acids resulted in lower enantioselectivities [52]. Excellent enantioselectivities were also obtained in the partial hydrogenations of substituted 2-pyrones over these chiral Pd catalysts [53]. Although Pt and Pd catalysts modified by cinchona alkaloids were found to be remarkably efficient in the enantioselective hydrogenation of activated ketones and $\alpha, \beta$-unsaturated carboxylic acids, respectively, these catalysts were less appropriate for the enantioselective hydrogenation of N-heterocyclic compounds [54-56].<smiles>[R]/C(=C/c1ccc([X])cc1)C(=O)O</smiles><smiles>[R]OCCCC</smiles><smiles>[X]c1ccc(CC([R])C(=O)O)cc1</smiles>

$\mathrm{X}=\mathrm{F}, \mathrm{R}=2-\mathrm{Methoxyphenyl:} \mathrm{ee}=96 \%$<smiles>[R]Oc1cc(C)oc(=O)c1</smiles><smiles>[R]OC1=CC(=O)O[C@@H](C)C1</smiles>

$\mathrm{R}=\mathrm{H}:$ ee $=85 \%$

$\mathrm{R}=$ Methyl: $e e=94 \%$

Scheme 8. Enantioselective hydrogenations of prochiral $C=C$ groups over cinchona alkaloid-modified Pd catalysts [49-53]. 
In the latter two heterogeneous asymmetric catalytic systems The most efficient chiral modifiers for obtaining chiral Pt or Pd catalysts were the readily available and inexpensive natural cinchona alkaloids with the pseudoenantiomeric forms, cinchonidine (CD) and cinchonine $(\mathrm{CN})$ or quinine $(\mathrm{QN})$ and quinidine $(\mathrm{QD})$, their $\mathrm{C9}-\mathrm{O}$ methyl ethers and the 10,11-dihydro derivatives (Figure 2), which are among the most privileged chirality inducers in the area of asymmetric catalysis [57]. Cinchona alkaloids are extracted from the bark of the cinchona trees, which occur in Africa, Latin America, and Indonesia. Approximately 700 metric tons of cinchona alkaloids are harvested annually. The main feature responsible for their successful use in asymmetric catalysis is their chiral skeleton (Figure 3) and the functional groups which are easily tuneable for diverse types of reactions.

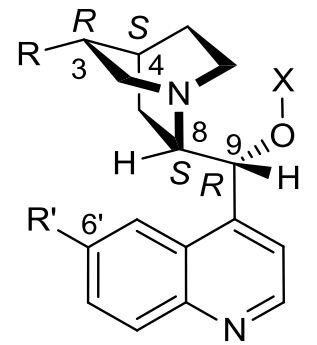

cinchonidine (CD): $X=H, R=V i n y l, R^{\prime}=H$ dihydrocinchonidine: $X=H, R=E t h y l, R^{\prime}=H$ cinchonidine methyl ether: $\mathrm{X}=$ Methyl, $\mathrm{R}=\mathrm{Vinyl}, \mathrm{R}^{\prime}=\mathrm{H}$ quinine (QN): $X=H, R=V i n y l, R^{\prime}=M e O$

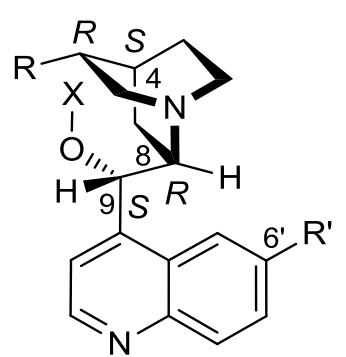

cinchonine $(\mathbf{C N}): X=H, R=V i n y l, R^{\prime}=H$ dihydrocinchonine: $X=H, R=E$ thyl, $R^{\prime}=H$ cinchonine methyl ether: $X=M e t h y l, R=V i n y l, R^{\prime}=H$ quinidine (QD): $X=\mathrm{H}, \mathrm{R}=\mathrm{Vinyl}, \mathrm{R}^{\prime}=\mathrm{MeO}$

Figure 2. Structures of the most effective cinchona alkaloid chiral modifiers.

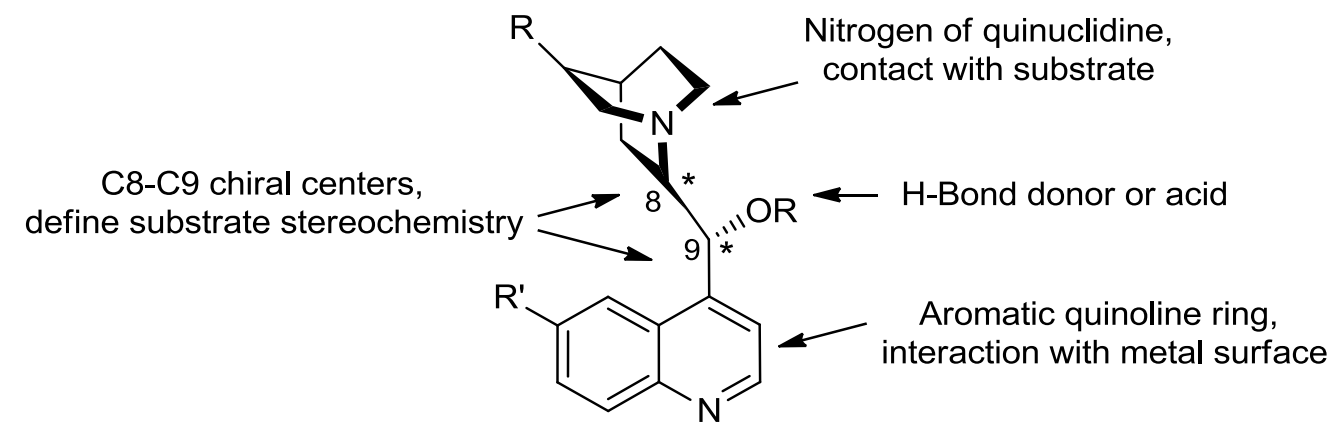

Figure 3. Role of the cinchona alkaloid molecule features in the Orito reaction [44,57].

\subsection{Heterogeneous catalytic reduction of aromatic nitro compounds}

The reduction of aromatic nitro compounds is a synthetically important reaction both in the laboratory and in industry, being among the convenient ways of introducing amino group in organic molecules and preparing N-heterocyclic compounds. Due to its importance several methods have been developed for this purpose. Among the reduction methods of the 
nitro group catalytic hydrogenation has been frequently employed as the most preferred processes for the synthesis of amines from nitro compounds, because in most cases the nitro group is hydrogenated readily over usual transition metal catalysts, separation of the products and catalysts are relatively simple, and very pure amines are obtained in high yields. Accordingly, the hydrogenation of aromatic nitro compounds with heterogeneous catalysts is in many cases the method of choice for the production of the corresponding anilines [32,58].

The catalytic hydrogenation of nitroarenes occurs easily under low hydrogen pressure at room temperature in liquid phase. The hydrogenations are accomplished generally in ethanol and addition of more than $10 \%$ water to the mixture may increase the hydrogenation rate, similarly to the use of one equivalent hydrochloric acid, acetic acid or the presence a small amount of sodium hydroxide. The most frequently used catalysts for the hydrogenation of nitro groups are the noble metals Pt and Pd supported on active carbon due to their high activity and selectivity, however, the cheaper Raney nickel, and supported Ni catalysts are also frequently applied [32]. More than a century ago Leipzig [59] proposed a reaction network to explain the results of the electrochemical reduction of nitrobenzene. Since then the intermediates he suggested have all been verified and it has been shown that catalytic hydrogenation reactions proceed via the suggested routes (Scheme 9).

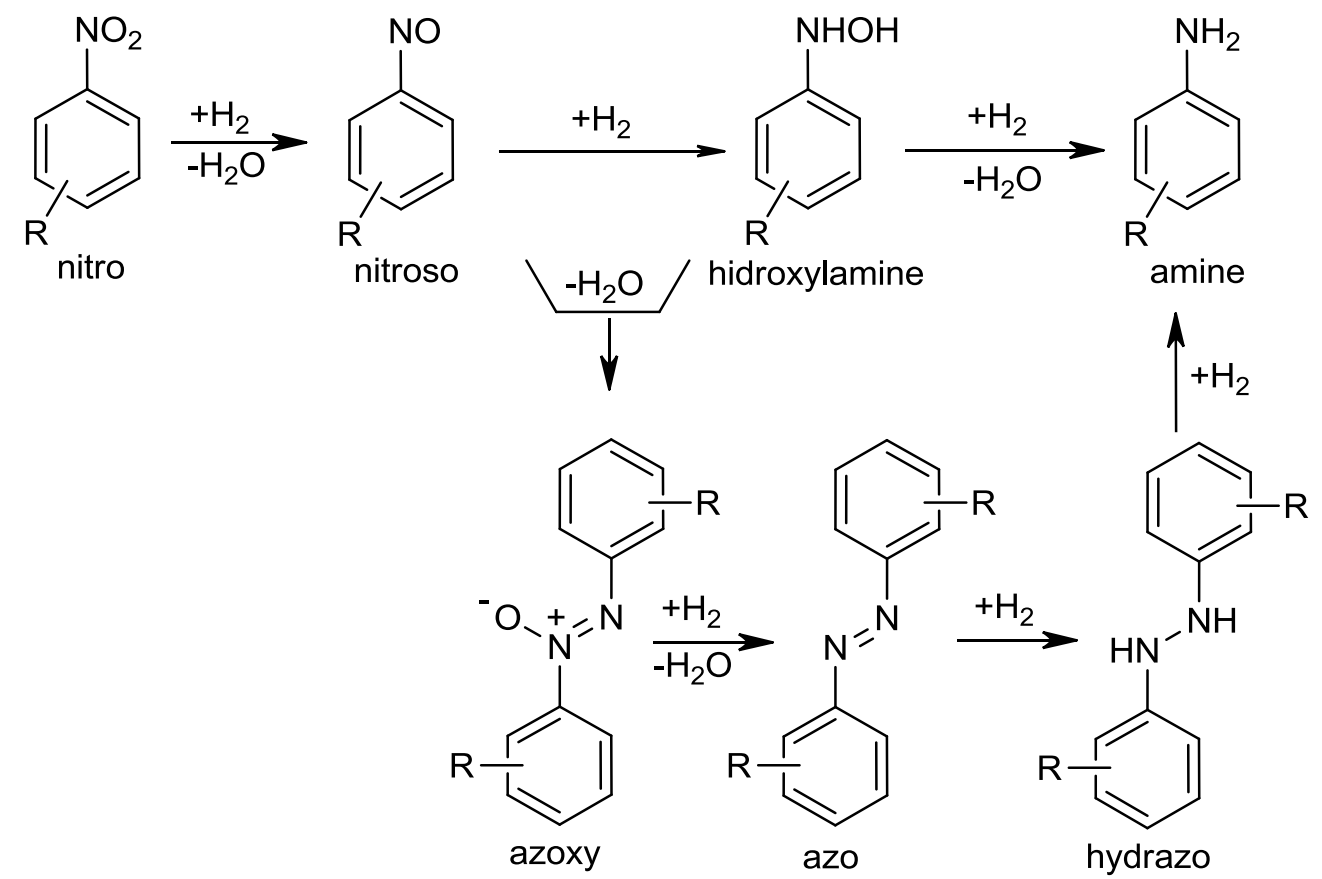

Scheme 9. Hydrogenations of aromatic nitro compounds over heterogeneous catalysts [35]. 
It is of paramount importance from the selectivity viewpoint that nitroarenes are adsorbed rather strongly by the catalyst surface, reduction of the other reducible groups normally starts only when the nitro groups have been transformed. The application of organic modifiers and additives is an important strategy for influencing the properties, mainly selectivity, of heterogeneous catalysts as summarized by Freifelder [60] and later by Nishimura [32]. The hydrogenation to aromatic amines occurs through several stable intermediates as shown in Scheme 9, among which are also condensed products, which by further reduction may give the final amino compounds, however these intermediates are isolable under the appropriate reaction conditions. The possibility of formation of several stable intermediates and side-products makes exceedingly significant the proper choice of the reaction conditions for specific tasks and also makes necessary optimization studies for each substrate to find the appropriate reactant structure-reaction conditions correlation.

The selectivities in the hydrogenation of functionalized nitroarenes was studied by Blaser and co-workers a few years ago [61]. The performance of new catalyst types was described, most notably of gold-based catalysts, but also of modified classical Pt, Pd, and Ni catalysts, as well as homogeneous catalysts. These catalytic systems were capable of reducing nitro groups with very high chemoselectivity in substrates containing carbon-carbon or carbon-nitrogen double or triple bonds, carbonyl or benzyl groups, and multiple halogen substituents (Figure 4). Accordingly, the selective hydrogenation of a keto group near the nitro group is a very demanding task.<smiles>CC(=O)c1ccc([N+](=O)[O-])cc1</smiles>

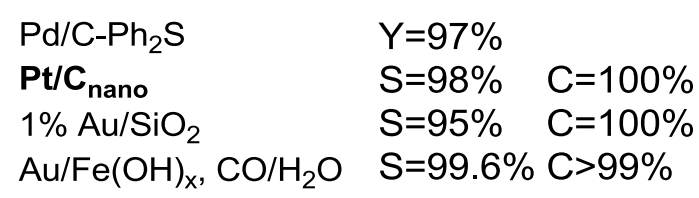

Figure 4. Selected results for the hydrogenation of a nitroarene incorporating carbonyl group (Y: yield, S: selectivity of the keto-aniline derivative, C: conversion) [61].

The hydrogenation of the aromatic nitro derivatives bearing certain functional groups in appropriate positions may lead to ring closure after the reduction of the nitro group to amino group. Thus the preparation of $\mathrm{N}$-heterocycles, such as indole or quinoline derivatives is possible in a one-pot process. The most effective functional groups for performing such reactions are halogens, carbonyl groups, carboxylic acids and esters. Cyclization of the last 
two compounds results in the formation of quinoline derivatives, as shown in Scheme 10 $[32,62,63]$. However, until now only one example of asymmetric formation of $\mathrm{N}$-heterocyclic compounds has been described using one-pot cascade reduction of a nitro group and spontaneous cyclization, which was performed over cinchona alkaloid modified Pd catalyst and resulted in moderate, up to $37 \%$ enantioselectivities, of 3-phenyl-3,4-dihydroquinolin2(1H)-ones products (Scheme 11) [64].

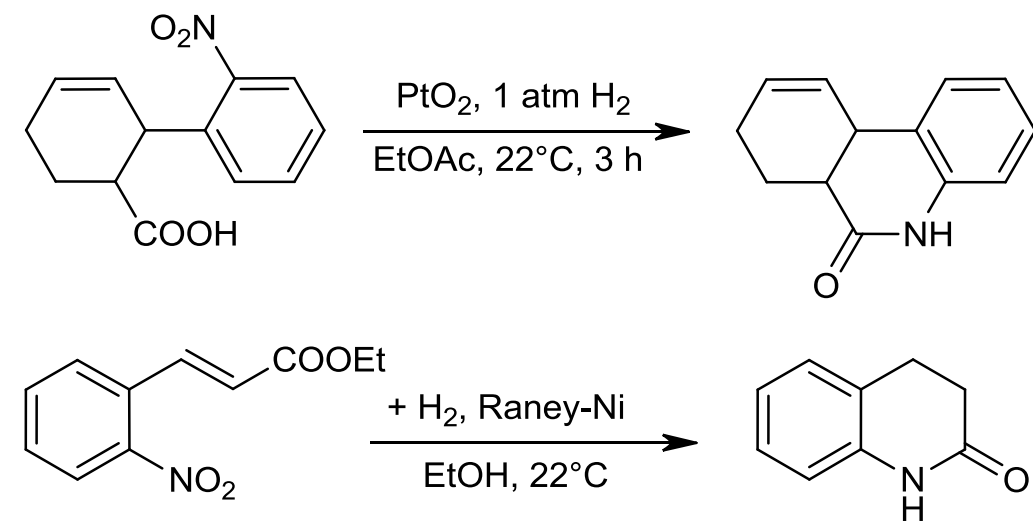

Scheme 10. Ring closing reactions after reduction of aromatic nitro compounds [32].<smiles>[X]c1ccccc1[C@H](S)Cc1ccccc1N</smiles>

Scheme 11. Asymmetric preparation of quinolone derivatives over cinchonidine-modified Pd catalyst [64].

\subsection{Asymmetric hydrogenations in continuous-flow systems}

One of the most important advantage of heterogeneous catalytic systems is their easy feasibility to continuous processes. The use of continuous-flow systems in which the catalyst is placed in fixed-bed reactors makes possible to save the catalyst removal step from the product mixture. Moreover, there are other significant advantages of continuous-flow systems 
such as the possibility of easy automation, good reproducibility, increased safeness and process reliability by allowing constant reaction parameters (time, temperature, amount of reagents, solvent, etc.) [65]. The continuous-flow operation mode besides the possibility of process intensification also allows carrying out hazardous reactions via highly reactive intermediates. A current trend in the synthetic organic chemistry is the use of continuous-flow processes, which can be performed most advantageously by using modern immobilized reagents or catalysts [66-68].

Asymmetric reactions, especially enantioselective heterogeneous catalytic hydrogenations, were also attempted in continuous-flow reactor systems. The first study on the Orito reaction in a continuous-flow system was reported by Wells and co-workers, who studied the enantioselective hydrogenation of methyl pyruvate [69]. Following this study Baiker's group investigated the reactions of ethyl pyruvate and ketopantolactone in a continuous-flow system [70]. While the hydrogenation of $\alpha$-keto esters was successful in continuous systems over Pt catalysts, in the enantioselective hydrogenations of prochiral olefins over modified Pd catalyst, lower enantioselectivities [71], or good enantioselectivities in the hydrogenations of 2-pyrone derivatives accompanied by low yields were reported [72].

During the last decade flow chemistry became a technique for improving and simplifying the synthesis of fine chemicals [73-76]. To satisfy the need for easily operated flow systems several producers developed and commercialized flow apparatus for carrying out reactions at laboratory scale. Such a system is the H-Cube system a revolutionary benchtop standalone continuous-flow hydrogenator equipped with a fixed bed reactor (Figure 5).

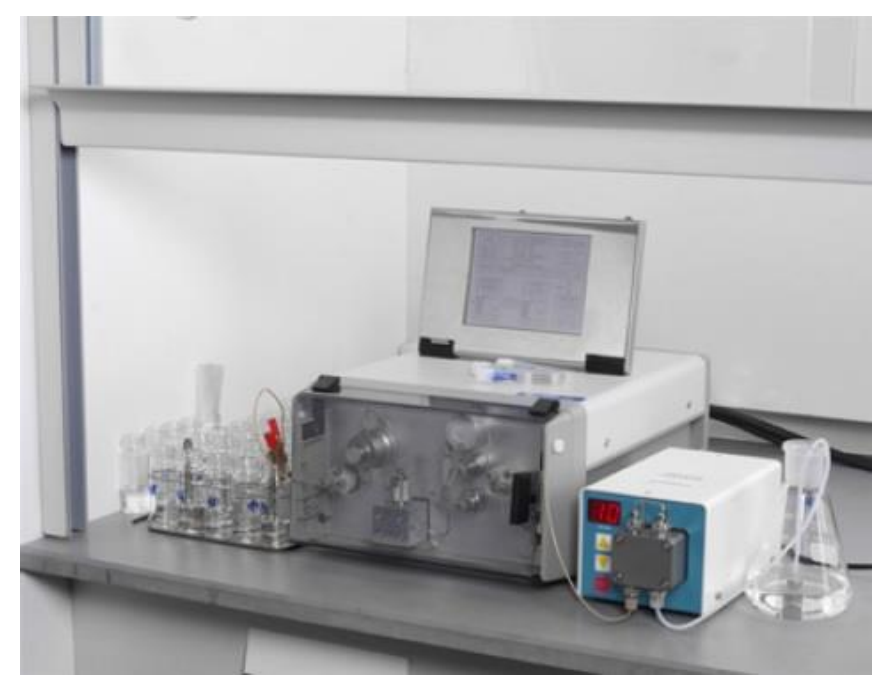

Figure 5. H-Cube continuous-flow apparatus. 
The apparatus combined continuous-flow microchemistry with adjustable hydrogen generation and a disposable catalyst cartridge system. Continuous production of hydrogen, generated through the electrolysis of deionized water was mixed with the substrate stream and passed into reactor. This apparatus allowed fast and cost-efficient hydrogenation with superior yields when compared to conventional methods as reported in the first publications appeared in 2005 on its successful utilization to carry out heterogeneous hydrogenations [77-79].

In our research group the enantioselective hydrogenations of ethyl pyruvate, ketopantolactone and methyl benzoylformate in the H-Cube continuous-flow system using fixed-bed reactor over Pt catalyst modified by cinchona alkaloids was studied, previously not attempted in this apparatus [80]. Later the enantioselective hydrogenation of $\alpha, \beta$-unsaturated carboxylic acids of various structures was also studied in the same reactor system over Pd catalysts [71]. It was found, that studies on the enantioselective hydrogenation of activated ketones in continuous flow system may shed light on additional details of the reaction mechanism, which couldn't be observed in batch reactor. These experimental results showed that the H-Cube flow hydrogenator is also feasible for studying the mechanism of heterogeneous catalytic asymmetric hydrogenations or other catalytic reactions.

\subsection{Heterogeneous asymmetric cascade reactions}

Our research was commenced hoping the development of a novel asymmetric heterogeneous cascade reaction for the preparation of optically enriched 3-hydroxy-2hydroquinolone derivatives based on the report of Murakami and co-workers discussed previously [33]. A cascade reaction, also known as domino reaction or tandem reaction, is a chemical process in which at least two consecutive steps occur, therefore incorporate multiple bond-forming events carried out in one-pot manner [81]. Furthermore, no additional reagents, catalysts, or additives are added to the reaction vessel, nor the reaction conditions are changed [27]. Isolation of intermediates is not required, as each reaction composing the sequence occurs spontaneously. In 1917 synthesis of tropinone (a precursor of cocaine) by Robinson, was the earliest example of a cascade reaction [82]. Since then a huge interest in the use of cascade reactions was observed, reflected by the numerous relevant review articles published on cascade sequences [27,83-87]. A rapidly growing area is the development of asymmetric catalytic cascade processes which employ chiral organocatalysts or chiral transition-metal complexes $[83,87]$. Although, numerous asymmetric catalytic cascade reactions have been 
developed for the synthesis of chiral fine chemicals, only few enantioselective cascade or domino reactions over heterogeneous chiral catalysts are known [64,88-97].

A highly efficient cascade over Pt catalyst modified by cinchona alkaloids was observed by the hydrogenation of 2-ketoglutaric acid, which was followed by spontaneous cyclization to optically enriched 5-oxotetrahydrofuran-2-carboxylic acid in quantitative yield (Scheme 12) [97]. High enantioselectivities, typical to the hydrogenation of a-keto esters and acids were obtained in this enantioselective hydrogenation-cyclization cascade even in water.
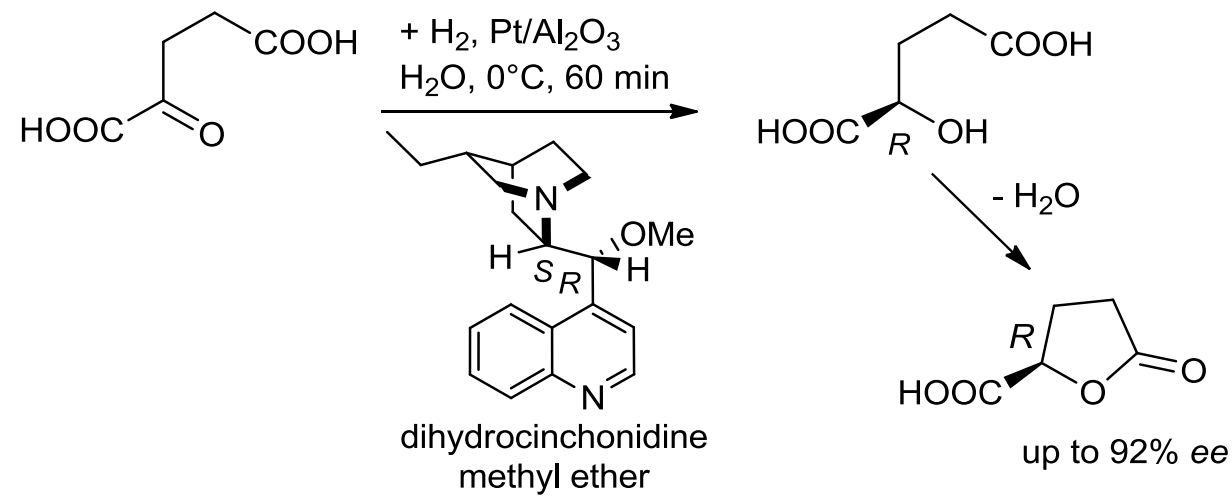

Scheme 12. Asymmetric cascade reaction of 2-ketoglutaric acid [97].

Recently, several research groups developed highly efficient asymmetric cascade reactions in which the use of surface-bonded heterogenized chiral organocatalysts, such as the cinchona alkaloid derivatives bonded to $\mathrm{Fe}_{3} \mathrm{O}_{4}$ nanoparticles used in inverse electron demand Diels-Alder cascade reaction for the preparation of cyclohexene derivatives in high yields and excellent optical purities [93]. Interesting asymmetric cascade reaction was developed by using the synergistic catalytic system obtained by immobilization of a chiral organocatalysts, i.e. diphenylprolinol trimethylsilyl ether, and $\mathrm{Pd}(\mathrm{II})$ by complexation to achiral surface aminoalkyl groups. The catalyst was used in a Michael reaction/carbocyclization cascade, which resulted in highly substituted cyclopentenes in high enantioselectivities [94].

Domino or cascade processes were also attempted in continuous-flow systems which gives the opportunity of convenient preparation of complex organic compounds [86,98-101]. In such systems several consecutive reactions with the ulterior transformation of functional groups formed in a previous step may be performed by a single passage of the reactant solution over a suitable catalyst bed. However, only one report was published until now on the application of heterogeneous chiral catalyst to promote asymmetric cascade reactions in a flow system [102]. In this study the authors used diarylprolinol trimethylsilyl ether 
immobilized on polystyrene resin as catalyst for the batch or flow preparation of optically enriched cyclohexanone by a Michael-Knoevenagel cascade reaction. The chiral product was subsequently reduced by $\mathrm{NaBH}_{4}$ to obtain cyclohexanol derivatives with four chiral centres in the molecule (Scheme 13).

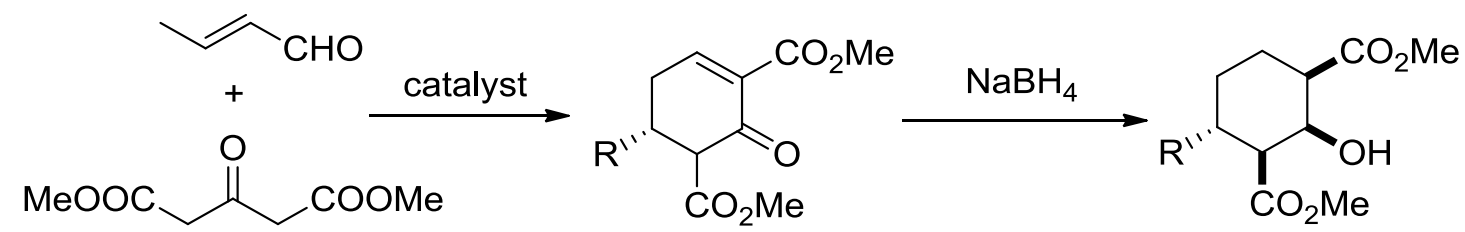

Scheme 13. Enantioselective synthesis of cyclohexane derivatives by heterogeneous cascade reaction in flow system [102].

These experimental results indicated that heterogeneous asymmetric domino or cascade reactions are among the novel, modern, environmentally benign procedures, which may assure the sustainable preparation of optically pure building blocks necessary in the pharmaceutical industry. Accordingly, our aim was to develop a novel heterogeneous cascade method for the enantioselective preparation of chiral tetrahydroquinolone derivatives using supported Pt catalysts modified by cinchona alkaloids. The inspiration to begin this research was given by the method described recently using unmodified $\mathrm{PtO}_{2}$ as catalyst [33]. Having in sight several characteristics of the enantioselective hydrogenation of activated ketones over cinchona alkaloid modified Pt catalysts, such as the high enantioselectivities obtained and the intrinsic feature of acceleration of the chiral hydrogenations we hoped that in this system the asymmetric heterogeneous catalytic cascade reaction of 2-nitrophenylpyruvate derivatives will afforded optically enriched 3-hydroxy-3,4-dihydroquinolin-2(1H)-one derivatives in good yields and high enantioselectivities. We also planned to investigate this cascade reaction both in batch and flow systems. 


\section{EXPERIMENTAL}

\subsection{Materials and methods}

Commercial 5\% $\mathrm{Pt} / \mathrm{Al}_{2} \mathrm{O}_{3}$ (Engelhard, 4759), with known properties [103,104] was pre-treated in $\mathrm{H}_{2}$ flow at $673 \mathrm{~K}$ before use. Cinchona alkaloids were purchased from Alfa Aesar or Sigma-Aldrich or prepared by known procedures [105]. 2-Nitrophenylpyruvic acid, 2-nitrotoluene derivatives, diethyl oxalate and potassium tert-butoxide used for the preparation of ethyl 2-nitrophenylpyruvates substituted in various positions were purchased from Sigma-Aldrich. Analytical grade solvents and reagents were also purchased from SigmaAldrich and were used as received.

Products resulted in preparative reactions and catalytic studies were identified by gas chromatography coupled with mass spectroscopy (GC-MSD) using Agilent Techn. 6890N GC - 5973 inert MSD equipped with HP-1MS $60 \mathrm{~m}$ x $0.25 \mathrm{~mm}$ i.d. capillary column. Analysis conditions were: oven temperature $100{ }^{\circ} \mathrm{C}$ for $10 \mathrm{~min}, 10{ }^{\circ} \mathrm{C} \min ^{-1}$ to $200{ }^{\circ} \mathrm{C}$ and $200{ }^{\circ} \mathrm{C}$ for $100 \mathrm{~min}$, head pressure 22 psi. The purified compounds were also identified by NMR spectroscopy $\left({ }^{1} \mathrm{H}\right.$ and $\left.{ }^{13} \mathrm{C}\right)$ recorded on an AVANCE DRX 400 NMR instrument using $\left(\mathrm{CH}_{3}\right)_{4} \mathrm{Si}$ as internal standard in $\mathrm{CDCl}_{3}$ solvent. The chiral products resulted in the cascade reactions were analysed using GC equipped with flame ionization detector (FID): Agilent Techn. 6890N GC-FID. The enantiomeric separation was accomplished by using Cyclodex-B $30 \mathrm{~m}$ x $0.25 \mathrm{~mm}$ i.d. chiral capillary column. Optical rotation measurements were carried out using Polamat A polarimeter in $\mathrm{MeOH}(c 1, l 0.5, \lambda 546 \mathrm{~nm})$.

\subsection{Preparation of 2-nitrophenylpyruvic acid esters}

Ten 2-nitrophenylpyruvic acid esters (1a-1j, see Figure 6) were prepared according to literature procedures from commercially available materials.

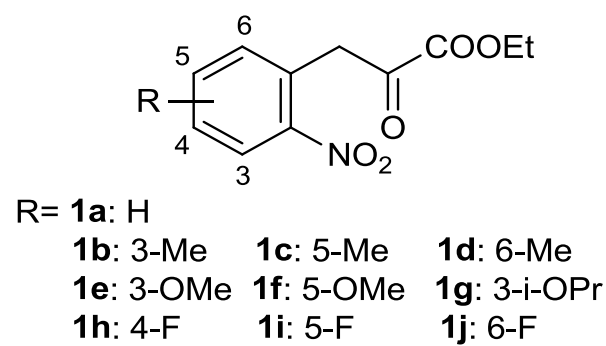

Figure 6. The structure of synthetized 2-nitrophenylpyruvates. 
Ethyl 2-nitrophenylpyruvate (1a) was prepared by esterification of 2nitrophenylpyruvic acid as follows. To $0.55 \mathrm{~g}(3.2 \mathrm{mmol})$ para-toluenesulfonic acid dissolved in $100 \mathrm{~cm}^{3}$ EtOH a solution of $3 \mathrm{~g}(14.3 \mathrm{mmol})$ 2-nitrophenylpyruvic acid dissolved in $50 \mathrm{~cm}^{3}$ EtOH was added. The solution was refluxed overnight, the solvent was evaporated, and the oily residue was dissolved in $100 \mathrm{~cm}^{3}$ diethyl ether, washed twice with $10 \% \mathrm{Na}_{2} \mathrm{CO}_{3}$ solution, once with brine and dried over $\mathrm{Na}_{2} \mathrm{SO}_{4}$. The ether was evaporated to give ethyl 2nitrophenylpyruvate as a pale yellow oil which according to ${ }^{1} \mathrm{H}$ NMR, GC-MSD and GC-FID analysis was of over 97\% purity and was used without further purification; yield: $3.26 \mathrm{~g}$ $(96 \%)$.

Substituted 2-nitrophenylpyruvates $(\mathbf{1 b}-\mathbf{1 j})$ were prepared by a literature method according to Scheme 14 [33].

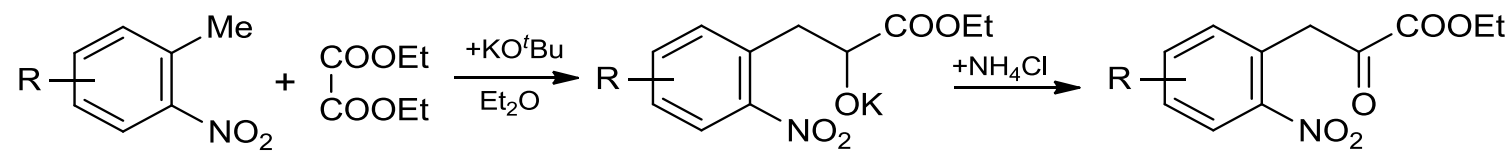

Scheme 14. Preparation of substituted 2-nitrophenylpyruvates.

In a typical reaction to a vigorously stirred suspension of $9 \mathrm{~g}(80 \mathrm{mmol}) \mathrm{KO}^{t} \mathrm{Bu}$ in 200 $\mathrm{cm}^{3}$ diethyl ether, $11 \mathrm{~cm}^{3}(80 \mathrm{mmol})$ diethyl oxalate was added followed after 10 min stirring by dropwise addition of $80 \mathrm{mmol}$ of the corresponding 2-nitrotoluene derivative. The suspension was stirred at room temperature for $24-48 \mathrm{~h}$. The reaction was quenched by addition of $150 \mathrm{~cm}^{3}$ saturated $\mathrm{NH}_{4} \mathrm{Cl}$ solution, the ethereal solution was separated, the aqueous phase was washed with $2 \times 100 \mathrm{~cm}^{3}$ ethyl acetate and the combined organic phases were dried overnight over $\mathrm{Na}_{2} \mathrm{SO}_{4}$. The solvents were removed by evaporation and the 2nitrophenylpyruvates were purified by flash chromatography using petroleum ether/ethyl acetate mixtures as eluent $(8 / 1-6 / 1)$. Products of at least $97 \%$ purity (unless otherwise noted) were obtained in $30-60 \%$ yields. The preparation of a few derivatives was carried out only on a $40 \mathrm{mmol}$ scale.

\subsection{Typical procedure of the asymmetric catalytic cascade reaction}

The cascade reactions were carried out using a stainless steel high-pressure autoclave equipped with a glass tube of $45 \mathrm{~cm}^{3}$ and two gas inlets (Figure 7). The reaction slurry was stirred magnetically at $1000 \mathrm{rpm}$. In a typical reaction the given amount of catalyst was 
suspended in $5 \mathrm{~cm}^{3}$ of the corresponding solvent followed by addition of the modifier and the 2-nitrophenylpyruvate derivative. The tube was placed in the autoclave, flushed with $\mathrm{H}_{2}$ five times and pressurized to the desired $\mathrm{H}_{2}$ pressure.

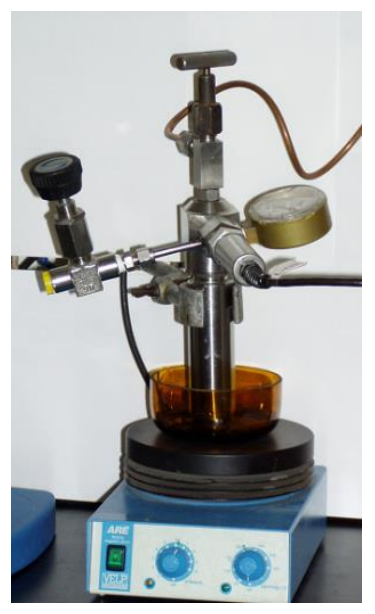

Figure 7. Stainless steel high-pressure autoclave.

The reaction was commenced by stirring the slurry. After the given reaction time the catalyst was filtered and washed twice with $3 \mathrm{~cm}^{3}$ solvent and the unified solutions were analysed by GC-MSD for product identification and by GC-FID using a chiral capillary column. Based on the later analysis conversions, selectivities and enantiomeric excesses (ee) were calculated with the formula:

$$
\begin{aligned}
& \text { Conversion }(\%)=100 \times \Sigma c\left(\mathrm{P}_{\mathrm{i}}\right) / c_{0} \\
& \operatorname{Sel}\left(\mathrm{P}_{\mathrm{i}}\right)(\%)=100 \times c\left(\mathrm{P}_{\mathrm{i}}\right) / \Sigma c\left(\mathrm{P}_{\mathrm{i}}\right) \\
& \operatorname{ee}\left(\mathrm{P}_{\mathrm{i}}\right)(\%)=100 \times\left[c\left(R-\mathrm{P}_{\mathrm{i}}\right)-c\left(S-\mathrm{P}_{\mathrm{i}}\right)\right] /\left[c\left(R-\mathrm{P}_{\mathrm{i}}\right)+c\left(S-\mathrm{P}_{\mathrm{i}}\right)\right],
\end{aligned}
$$

where „Pi" is the corresponding product; , , $c_{0}$, is the initial concentration of the substrate; $c\left(\mathrm{P}_{\mathrm{i}}\right)$ are the concentrations of products $\mathrm{P}_{\mathrm{i}}$ determenid by $\mathrm{GC} ; \operatorname{Sel}\left(\mathrm{P}_{\mathrm{i}}\right)$ are the selectivities of products $\mathrm{P}_{\mathrm{i}} ; c\left(R-\mathrm{P}_{\mathrm{i}}\right)$ and $c\left(S-\mathrm{P}_{\mathrm{i}}\right)$ are the concentrations of $\mathrm{P}_{\mathrm{i}}$ product enantiomers.

Following product analysis, the hydroquinolone derivatives were isolated by flash chromatography using petroleum ether/ethyl acetate eluent $(4 / 1-2 / 1)$ for determination of isolated yields, characterization by NMR spectroscopy and determination of the sign of the optical rotations. Based on the stereochemistry of the hydrogenations of $\alpha$-keto esters investigated up to now over Pt modified by CD [42-45], we assumed that the use of alkaloids from this series results in excess formation of the product enantiomer having $R$ absolute configuration. However, the configuration of the product was checked by reducing the 
purified product using $\mathrm{LiAlH}_{4}$ to 3-hydroxy-1,2,3,4-tetrahydroquinoline with known specific rotation [106].

\subsection{Hydrogenation procedure in flow system}

The flow experiments were carried out using a $\mathrm{H}-\mathrm{Cube}^{\circledR}$ continuous-flow hydrogenation system, purchased from Thales Nanotechnology Inc. [107] equipped with a high pressure pump (Knauer WellChrom HPLC-pump K-120). This apparatus includes a $\mathrm{H}_{2}$ generator and a cartridge used as a fixed-bed reactor, as shown in Figure 8.

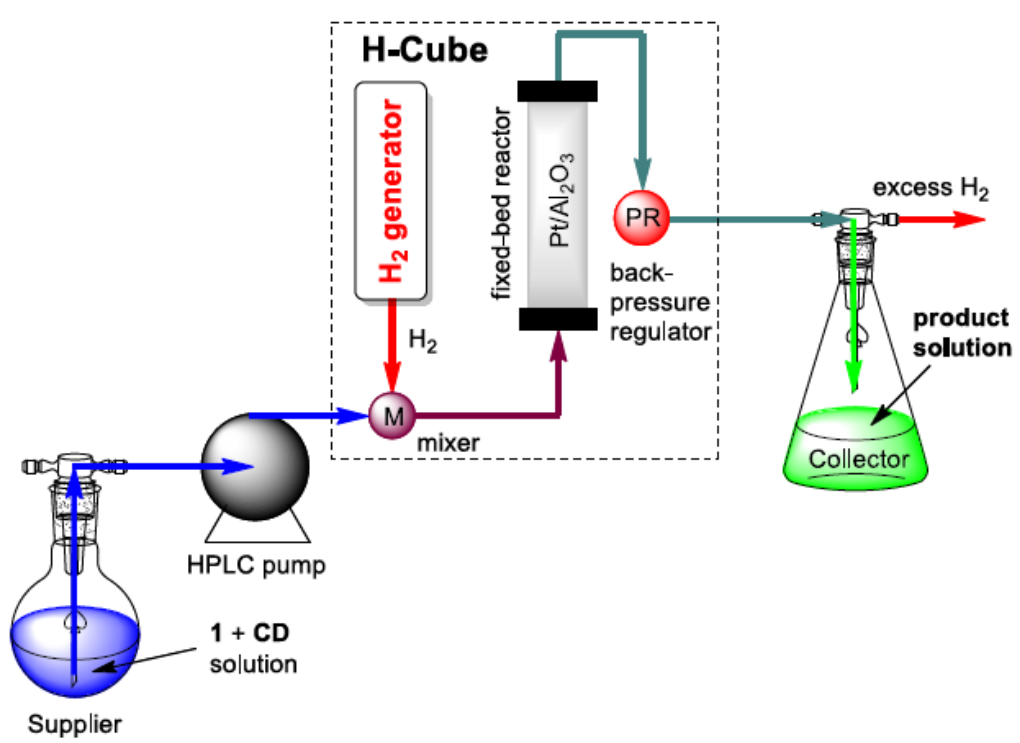

Figure 8. Scheme of the $\mathrm{H}$-Cube ${ }^{\circledast}$ continuous-flow hydrogenation apparatus.

In a typical experiment the given amount of catalyst pre-treated at $673 \mathrm{~K}$ in $\mathrm{H}_{2}$ flow was placed in the tubular catalyst cartridge of $2 \mathrm{~mm}$ inner diameter and $30 \mathrm{~mm}$ length. The catalyst was pre-hydrogenated in toluene flow under the given $\mathrm{H}_{2}$ pressure for $30 \mathrm{~min}$ and premodified with a flow of $\mathbf{C D}$ dissolved in toluene/AcOH mixture in presence of $\mathrm{H}_{2}$ for 30 min. Continuous-flow reactions were carried out by pumping through the system the solution of the substrate and the modifier at the desired flow rate and under the give $\mathrm{H}_{2}$ pressure at room temperature. Samples were collected at regular time intervals and analysed similarly as samples obtained in batch reactor. 


\section{RESULT AND DISCUSSION}

According to our aim based on the results published by Murakami and co-workers and relying on the accumulated experience in the research group on using chirally modified metal catalysts in the hydrogenation of various prochiral unsaturated compounds, we initiated a study on applying such catalysts for the asymmetric preparation of 3-hydroxyhydroquinolones. These studies were commenced by using the ester without any additional substituent, i.e. ethyl 2-nitrophenylpyruvate (1a), as test molecule, which according to the above mentioned report may provide only satisfactory results in a racemic reaction [33].

\subsection{Hydrogenation of 2-nitrophenylpyruvates in batch reactor}

The product mixture resulted in the reaction of $\mathbf{1}$ over $\mathrm{Pt} / \mathrm{Al}_{2} \mathrm{O}_{3}$ modified by $\mathbf{C D}$ four compounds were identified, as shown in Scheme 15. According to the Reissert indole synthesis, the corresponding indole (3) and oxindole (2) derivatives formed by complete or partial reduction of the nitro group to amino or aminohydroxyl groups and condensation of these with the keto group. The unmodified $\mathrm{Pt} / \mathrm{Al}_{2} \mathrm{O}_{3}$ catalyst provided a product mixture containing N-hydroxyindole (2) as the most abundant component (60\%), which is formed by cyclization of the partially reduced hydroxylamine intermediate [108]. The presence of CD increased the amount of our target product, i.e. the 3-hydroxy-3,4-dihydroquinolin-2(1H)-one derivate (5) from $10 \%$ to $36 \%$ in the reaction of 1a. In the reaction mixture we also identified the amino-alcohol derivate (4), which remained due to incomplete cyclization to $\mathbf{5}$. Both chiral products were formed in identical, but low ee (44\% in the reaction of 1a).<smiles>[R][R]c1ccc2c(c1)C[C@@H](O)C(=O)N2</smiles>

Scheme 15. Products formed in the asymmetric catalytic cascade reaction of 2-nitrophenylpyruvates over $\mathrm{Pt} / \mathrm{Al}_{2} \mathrm{O}_{3}$. 
According to these initial results, similarly as pointed out by Murakami and coworkers [33], the preparation of the hydroquinoline derivatives was possible over supported Pt catalyst, moreover chiral modification by cinchona alkaloids increased the selectivity of the desired product 5. Although, low ee was obtained in this preliminary study the ee value exceeded the one reported in the hydrogenation of activated benzyl ketones over Pt modified by CD [109]. Thus, based on both the selectivity and the ee obtained, we thought worth studying the effect of the reaction conditions for finding possibilities of increasing these values in this novel asymmetric cascade reaction.

\subsubsection{Solvent effect}

The solvent may have a significant effect on the hydrogenation rate of the functional groups, as well as on the ee obtained in the hydrogenation of activated ketones over $\mathrm{Pt}$ catalysts modified by cinchona alkaloids [42-45]. Accordingly, initially we have studied the effect of different solvents on the reaction out-come. In the report of Murakami and coworkers higher 3-hydroxy-3,4-dihydroquinolin-2 $(1 H)$-one yields were obtained in reactions of 2-nitrophenylpyruvates substituted next to the nitro group on the phenyl ring [33]. This was explained by steric reasons, namely, the adjacent substituent decreases the reduction rate of the nitro group. Thus, in our studies on the effect of the reaction conditions besides nonsubstituted 1a the 3-methyl substituted 1b (ethyl 2-nitro-3-methylphenylpyruvate) was also used. Results obtained in various solvents are summarized in Table 1.

In several polar protic and aprotic solvents good over 50\% 5a selectivities were obtained. It is known that toluene $(\mathrm{T})$ and acetic acid $(\mathrm{AcOH})$, and their mixtures are the best performing and most often used in the enantioselective hydrogenation of $\alpha$-keto esters over $\mathrm{Pt}$ catalysts modified with cinchona alkaloids [42-45]. Therefore, we decided to investigate the reaction in $\mathrm{T}$ and $\mathrm{T}$ with addition of small amount of $\mathrm{AcOH}$, which was used because of low solubility of some products in pure T. On the other hand, the indole (3) selectivity increased to $38 \%$ in pure $\mathrm{AcOH}$ (not shown in Table 1). The best enantioselectivities were obtained in these solvent mixtures in the reaction of both test compounds (up to 75\%). However, the examined 1a and 1b compounds showed different behaviours, the best selectivities and ee values were obtained under slightly different reaction conditions in the reaction of the two compounds. Thus, the reaction of $\mathbf{1 a}$ was most efficient in $10 \mathrm{vol} \% \mathrm{AcOH}$ containing mixture, in contrast to the reaction of $\mathbf{1 b}$, in which the best results $(\operatorname{Sel}(\mathbf{5 b}) 92 \%$ and ee $72 \%$ ) were obtained in a mixture containing only 2 vol\% AcOH. 


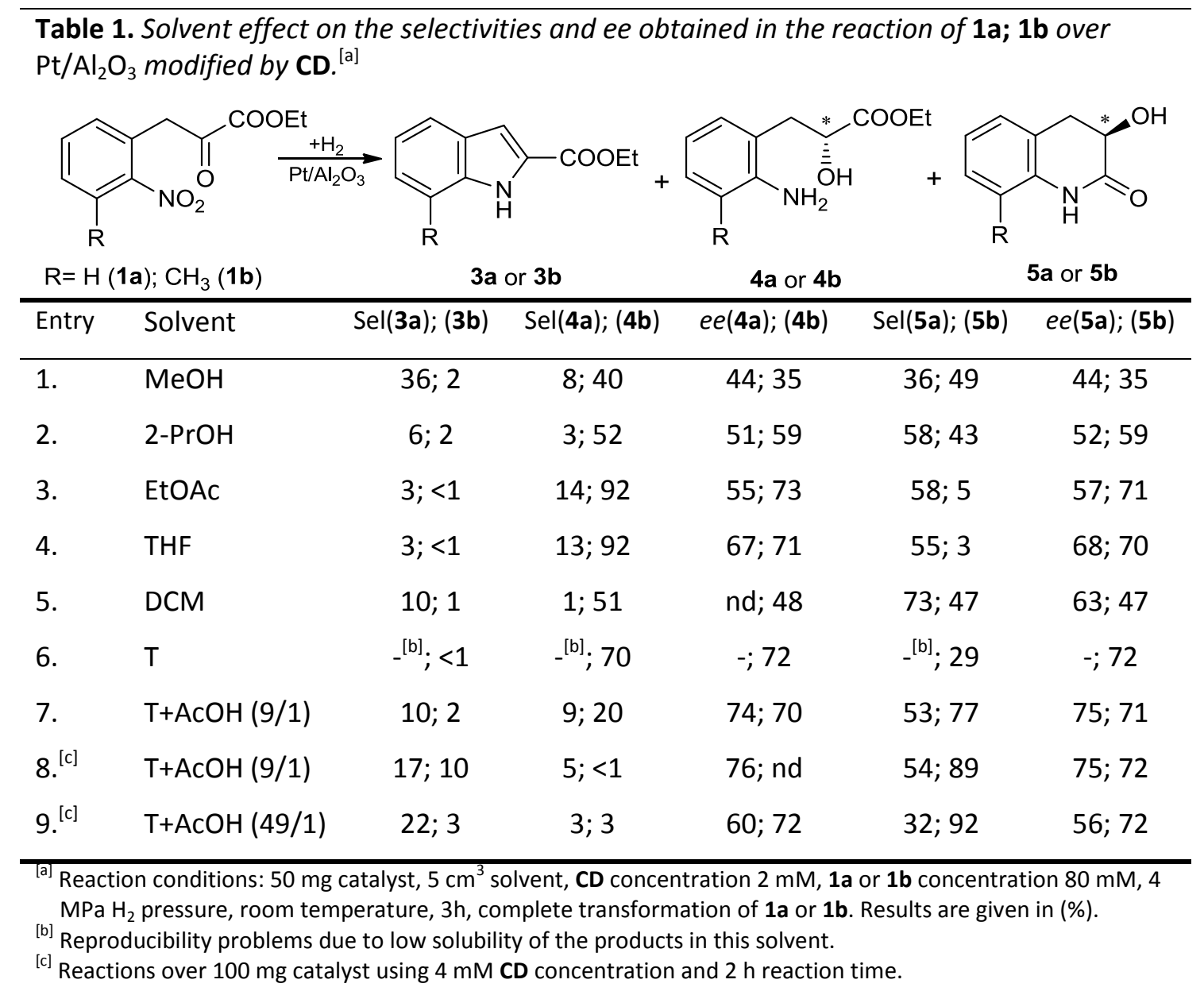

\subsubsection{Influence of the AcOH and catalyst amount.}

Due to the important role of $\mathrm{AcOH}$ in determining the selectivities and $e e$ obtained in the cascade reaction, the effect of the $\mathrm{AcOH}$ amount was investigated in more detail. Results obtained in the reaction of $\mathbf{1 b}$ are showed in Figure 9. Complete conversion of $\mathbf{1 b}$ was always obtained under these experimental conditions. A small increase in the ee was obtained by increasing the amount of $\mathrm{AcOH}$ up to 5 vol\%; however, the ee values did not change considerably when the $\mathrm{AcOH}$ content of the solvent was further increased. The selectivities obtained indicated that the presence of the acid promotes cyclization shown by the obtained amount of $\mathbf{3 b}$ without addition of $\mathrm{AcOH}$. The acid also has an accelerating effect on the reduction of the nitro group, as indicated by the selectivity for $\mathbf{4 b}$. On the basis of these results, 2 vol\% AcOH was sufficient to obtain the best $\mathbf{5 b}$ selectivity and enantioselectivity. 


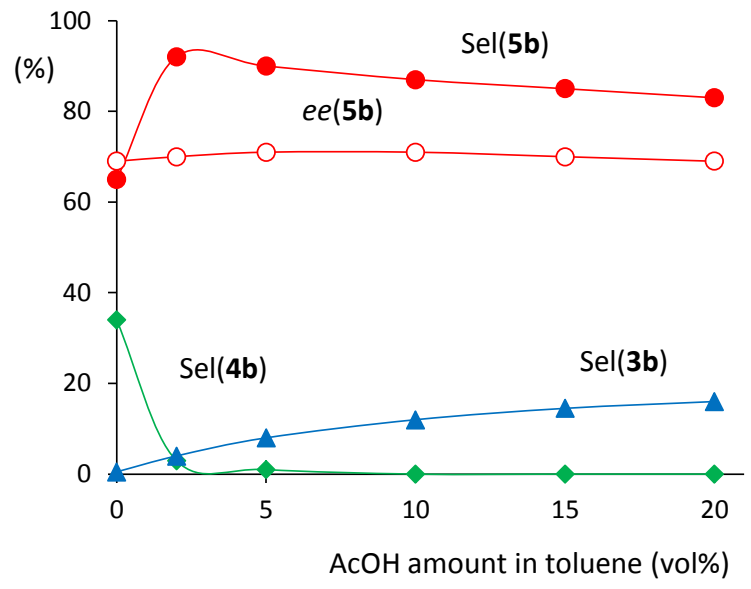

Figure 9. Effect of the $\mathrm{AcOH}$ amount on the product selectivities and ee in the reaction of 1b. Reaction conditions: $100 \mathrm{mg} \mathrm{Pt} / \mathrm{Al}_{2} \mathrm{O}_{3}, 5 \mathrm{~cm}^{3}$ of solvent, $c$ (CD) $4 \mathrm{mM}, c(\mathbf{1 b}) 80 \mathrm{mM}, p \mathrm{H}_{2} 4 \mathrm{MPa}$, $25^{\circ} \mathrm{C}$, $3 \mathrm{~h}$, full conversion of $\mathbf{1 b}$.

The next experiments were designed to investigate the role of the catalyst in the individual steps of the cascade reaction. We have used the above solvent mixture, and focused on examining the effect of the catalyst amount while keeping the $\mathbf{C D} /$ surface Pt ratio constant at 2.89 (the Pt dispersion according to literature data is 0.27 [110]).

As shown in Figure 10 over small amounts of catalyst (10 or $30 \mathrm{mg}$ ) both reducible groups $\left(\mathrm{C}=\mathrm{O}\right.$ and $\left.\mathrm{NO}_{2}\right)$ were completely hydrogenated and the main products were $\mathbf{4 b}$ and $\mathbf{5 b}$ even when 1b was not completely transformed. Over the whole range of the catalyst amount, the indole (3b) selectivity was low. The ee values of the two chiral compounds $\mathbf{4 b}$ and $\mathbf{5 b}$ were within the limit of the determination error. Over lower than $50 \mathrm{mg}$ catalyst when the conversion of $\mathbf{1 b}$ wasn't complete a significant decrease in the ee of $\mathbf{5 b}$ was detected. This decrease was probably due to lower CD concentration, which may diminish the $e e$ even when the $\mathrm{CD} /$ surface Pt ratio is kept constant, as effect of the dilution effect; thus, a higher ratio of surface sites is available for the racemic hydrogenation of the strongly adsorbing $\mathbf{1}[111,112]$.

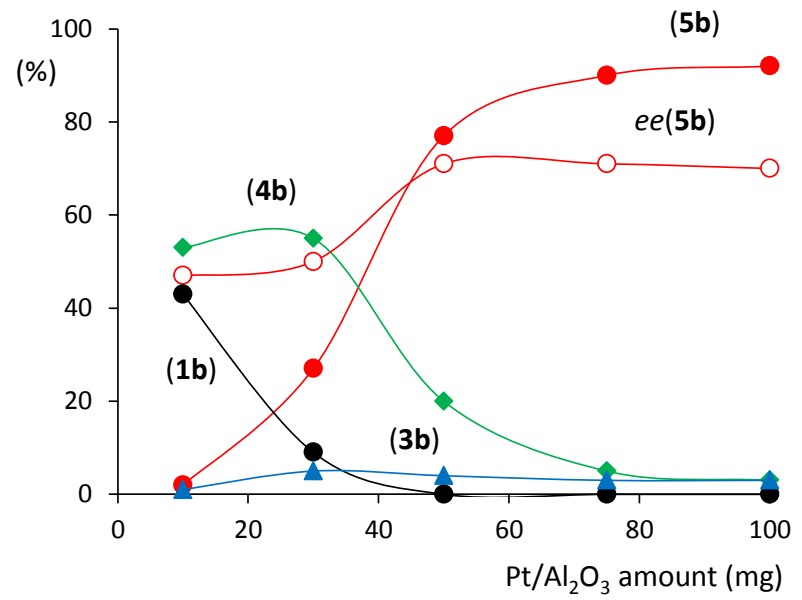

Figure 10. Effect of the catalyst amount on the product composition and ee in the reaction of $\mathbf{1 b}$.

Reaction conditions: $\mathrm{Pt} / \mathrm{Al}_{2} \mathrm{O}_{3}$ catalyst, $5 \mathrm{~cm}^{3}$ toluene with $2 \mathrm{vol} \% \mathrm{AcOH}, 2 \times 10^{-4} \mathrm{mmol} \mathrm{CD} / \mathrm{g}$ catalyst, $c$ (1) $80 \mathrm{mM}, p \mathrm{H}_{2} 4 \mathrm{MPa}, 25^{\circ} \mathrm{C}$, $3 \mathrm{~h}$. 
Although the effect of diffusion on the two reduction steps is difficult to examine due to fast competitive occurrence of these steps, the constant $e e$ over larger amounts of catalyst ( over $50 \mathrm{mg}$ ) is indicative of enantioselective hydrogenation without hydrogen diffusion limitation; otherwise, a decrease in ee would be observed [113]. We also mention that once formed, the chiral centre is not further affected in the successive transformations; thus, the obtained $e e$ values cannot provide further information on the kinetics of the following steps. However, an increase in the amount of $\mathbf{5 b}$ at the expense of $\mathbf{4 b}$ over a larger catalyst amount showed that the intramolecular amidation took place on the catalyst surface.

\subsubsection{Effect of the catalyst support}

According to the above results the final step of the cascade reaction, i.e. the intramolecular amidation, maybe catalysed by acids in liquid phase or may also occur on the catalyst surface following the consumption of $\mathbf{1 b}$. Hence, we examined the possible involvement of the catalyst support in the final cyclization, as the support may have acidic character, similar to the Pd catalyst supported over $\gamma-\mathrm{Al}_{2} \mathrm{O}_{3}$ of the same origin [114]. In order to study the role of the support, the reaction was carried out over Pt deposited on different supports, including a Lewis and Brønsted acidic clay (montmorillonite K-10) or Brønsted acidic Nafion ${ }^{\circledR}$ SAC-13. Results obtained are summarized in Table 2.

\begin{tabular}{|c|c|c|c|c|}
\hline Entry & Catalyst (mg) & Sel(4b) (\%) & Sel(5b) (\%) & $e e(\mathbf{5 b})(\%)$ \\
\hline 1. & $5 \% \mathrm{Pt} / \mathrm{Al}_{2} \mathrm{O}_{3}(50)$ & 20 & 77 & 71 \\
\hline 2. & $5 \% \mathrm{Pt} / \mathrm{Al}_{2} \mathrm{O}_{3}(100)$ & 6 & 90 & 76 \\
\hline 3. & $5 \% \mathrm{Pt} / \mathrm{C}(100)$ & $\leq 1$ & 71 & 36 \\
\hline 4. & $10 \% \mathrm{Pt} / \mathrm{C}(50)$ & $\leq 1$ & 77 & 36 \\
\hline 5. & $3 \% \mathrm{Pt} / \mathrm{SiO}_{2}(100)$ & 29 & 68 & 36 \\
\hline 6. & $\mathrm{PtO}_{2}(50)$ & $\leq 1$ & 88 & 24 \\
\hline 7. & $5 \% \mathrm{Pt} / \mathrm{K}-10(100)$ & 65 & 3 & 10 \\
\hline 8. & $5 \% \mathrm{Pt} / \mathrm{SAC}-13(50)$ & 95 & 3 & 23 \\
\hline 9. & $5 \% \mathrm{Pt} / \mathrm{Al}_{2} \mathrm{O}_{3}(50)+\mathrm{SAC}-13(50)$ & 57 & 42 & 59 \\
\hline
\end{tabular}


Large variations in enantioselectivities were obtained over the tested catalysts. The best values were attained over $\mathrm{Pt} / \mathrm{Al}_{2} \mathrm{O}_{3}$, whereas the worst with Pt supported over solid acids. Although the enantioselectivity is strongly influenced by the particle size and the morphology of Pt [44,115], the decrease in $e e$ observed after addition of Nafion ${ }^{\circledR}$ SAC-13 to the mixture using $\mathrm{Pt} / \mathrm{Al}_{2} \mathrm{O}_{3}$ indicated that a significant part of the modifier was bonded to the acidic material surface, impeding its adsorption on the metal. The selectivity of the quinolone $\mathbf{5 b}$ was very low over catalysts using acidic supports, whereas good selectivities were obtained over carbon or silica supported catalysts or even over in situ reduced $\mathrm{PtO}_{2}$. Accordingly, the support was not required to obtain the cyclic compound $\mathbf{5 b}$. The high $\mathbf{4 b}$ selectivities observed after addition of acidic material to the $\mathrm{Pt} / \mathrm{Al}_{2} \mathrm{O}_{3}$ containing slurry indicate an unfavourable effect of such materials on the cyclization. Thus, one may exclude the cyclization of $\mathbf{4 b}$ to $\mathbf{5 b}$ over the acidic support and consequently over $\mathrm{Al}_{2} \mathrm{O}_{3}$, and at this point we suggested that this final step also proceeds on the metal surface. This suggestion is also supported by known literature procedures, in which such lactams are prepared in neutral solvents by intramolecular amidation of esters with in-situ formed amino groups $[32,33,116]$. The significant effect of the support characteristics observed in this reaction may be attributed to the electronic charge transfer that occurred between metal and support, as was suggested to be the reason for the selectivities obtained in the competitive hydrogenation of different functional groups [117].

\subsubsection{Influence of the $\mathrm{H}_{2}$ pressure}

Confirmation of the suggestion that all three steps of the cascade reaction proceed over the Pt particles covered by chemisorbed hydrogen was obtained from studies on the effect of $\mathrm{H}_{2}$ pressure on the product formation shown in Figure 11 .

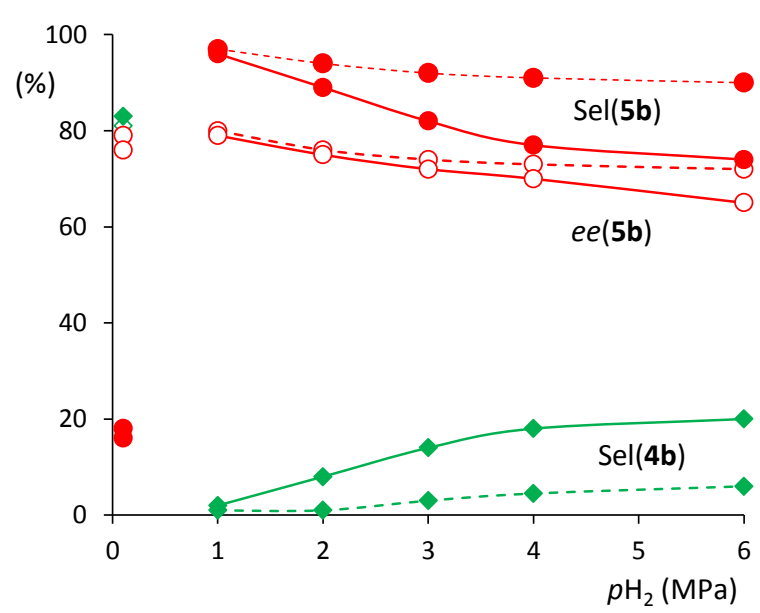

Figure 11. Effect of the $\mathrm{H}_{2}$ pressure on the reaction of $\mathbf{1 b}$.

Reaction conditions: $50 \mathrm{mg} \mathrm{Pt} / \mathrm{Al}_{2} \mathrm{O}_{3}, 3 \mathrm{~h}$ (solid line) or $100 \mathrm{mg} \mathrm{Pt} / \mathrm{Al}_{2} \mathrm{O}_{3}, 2 \mathrm{~h}$ (dotted line), $5 \mathrm{~cm}^{3}$ toluene with 2 vol\% AcOH, $2 \times 10^{-4} \mathrm{mmol} \mathrm{CD} / \mathrm{g}$ catalyst, c(1) $80 \mathrm{mM}, 25^{\circ} \mathrm{C}$, complete conversion of $\mathbf{1 b}$. 
The best results were obtained under $1 \mathrm{MPa} \mathrm{H}_{2}$ pressure. The increase in pressure over this value resulted in an increase in the selectivity of the unreacted $\mathbf{4 b}$ and a decrease in quinolone 5b selectivity. Similarly, under pressures over $1 \mathrm{MPa}$ the $e e$ also slightly decreased by increasing the pressure, as observed in enantioselective hydrogenations of activated ketones [115]. The most plausible explanation for the decrease in $e e$ is the consumption of the modifier by hydrogenation of the anchoring quinoline moiety of the cinchona alkaloid, resulting in formation of partially hydrogenated cinchonidine derivatives with lower enantiodifferentiating ability [118]. Considering that the selectivity for $\mathbf{5 b}$ followed the same trend as that of $e e$ as a function of $\mathrm{H}_{2}$ pressure, one may speculate that the cyclization is also unfavourably affected by the hydrogenation of CD. Possible interaction of $\mathbf{4 b}$ with partially hydrogenated CD on the Pt surface may decrease the cyclization rate by faster desorption of these molecules and may lead to higher concentration of the amino-alcohol product in the mixture following identical reaction time. Although this supposition should be verified in future experiments, if confirmed, these results support the assumption of the third step taking place on the Pt surface.

The selectivities obtained under low $\mathrm{H}_{2}$ pressure $(0.1 \mathrm{MPa})$ also worth discussing. The high amount of $\mathbf{4 b}$ detected in the reaction mixture should be due to low rates of the first two steps; thus, the third cyclization step of the cascade reaction was not complete following the given reaction time. This may also explain the low $\mathbf{5 b}$ selectivities obtained over home-made $\mathrm{Pt} / \mathrm{K} 10$ and Pt/SAC-13, which could have the same origin. These catalysts are probably less active in the reduction steps as compared with the commercial catalysts. Accordingly, the third step over these materials was not complete after identical reaction times as was used in experiments over commercial catalysts.

\subsubsection{Effect of the modifier structure and concentration}

Further increase of the selectivity and optical purity of the desired hydroquinolone derivatives was obtained by altering the structure of the modifier as shown in Figure 12. The best result was obtained using dHMCD (dihydrocinchonidine methyl ether) as modifier, although cinchona alkaloid methyl ethers provided better results as compared with the parent alkaloids in both cinchona series $\left(C^{8} S-C^{9} R\right.$ and $\left.C^{8} R-C^{9} S\right)$. Based on the stereochemistry of the hydrogenations of $\alpha$-keto esters investigated up to now over Pt modified by CD [42$45,119,120]$ we supposed that the use of alkaloids from this series results in excess formation of the $R$ enantiomer. The configuration of the product was checked by reducing the product 
formed in the cascade reaction of ethyl 2-nitrophenylpyruvate with $\mathrm{LiAlH}_{4}$ to 3-hydroxy1,2,3,4-tetrahydroquinoline with known specific rotation [106]. The $S$ product enantiomers were obtained by using cinchonine $(\mathbf{C N})$ and its derivatives, however, in lower selectivities and enantioselectivities as compared with the alkaloids from the CD series.

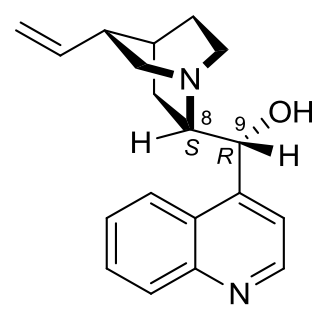

CD

(5a) $62 \%$, ee $=81 \%(R)$ (5b) $97 \%$, ee $=80 \%(R)$

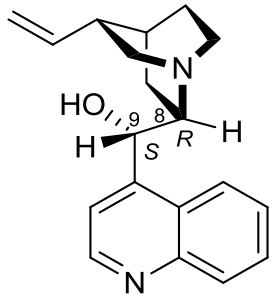

CN

(5a) $45 \%$, ee $=69 \%(S)$

(5b) $93 \%$, ee $=61 \%(S)$

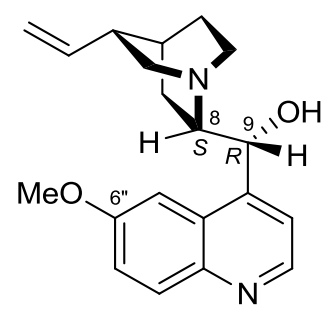

QN

(5b) $94 \%$, ee $=61 \%(R)$

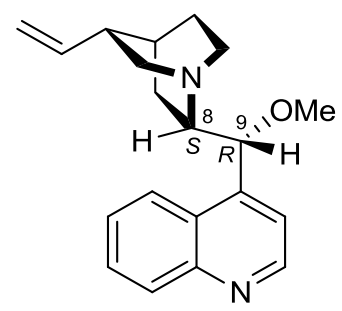

MCD

(5a) $60 \%$, ee $=83 \%(R)$

(5b) $99 \%$, ee $=82 \%(R)$

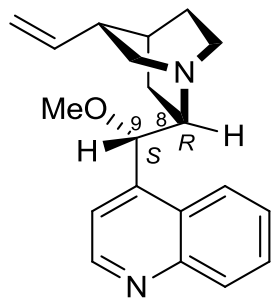

MCN

(5a) $64 \%$, ee $=82 \%$ (S)

(5b) $99 \%$, ee $=70 \%$ (S)

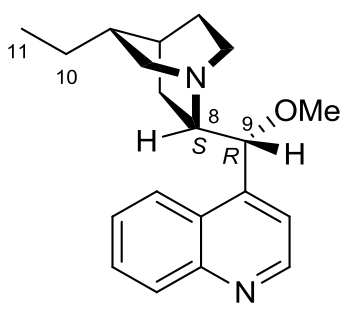

dHMCD

(5a) $70 \%$, ee $=90 \%(R)$

(5b) $99 \%$, ee $=90 \%(R)$

Figure 12. Selectivities and ees of 3-hydroxy-3,4-dihidroquinolin-2(1H)-ones obtained in reactions of $\mathbf{1 a}$ and $\mathbf{1 b}$ using various cinchona alkaloids as modifiers.

Reaction conditions: $c(\mathbf{1}) 80 \mathrm{mM}, 1 \mathrm{MPa} \mathrm{H}_{2}$ pressure, $25^{\circ} \mathrm{C}$; in reactions of 1a: $50 \mathrm{mg} \mathrm{Pt} / \mathrm{Al}_{2} \mathrm{O}_{3}, 5 \mathrm{~cm}^{3}$ toluene with 10 vol\% AcOH, $c$ (modifier) $2 \mathrm{mM}$, 3h; of $\mathbf{1 b}: 100 \mathrm{mg} \mathrm{Pt} / \mathrm{Al}_{2} \mathrm{O}_{3}, 5 \mathrm{~cm}^{3}$ toluene with 2 vol\% $\mathrm{AcOH}, \mathrm{c}$ (modifier) $4 \mathrm{mM}, 2 \mathrm{~h}$.

A study on the modifier concentration effect in the reaction of $\mathbf{1 b}$ showed the highest 5b selectivity at $4 \mathrm{mM} \mathrm{CD}$ concentration (Figure 13). However, the side products resulted at low and high $\mathbf{C D}$ concentrations differed, namely, $\mathbf{2 b}$ and $\mathbf{4 b}$, respectively. This phenomenon showed that the presence of adsorbed CD decelerates the reduction of the nitro group. At low modifier amount this is less accentuated, allowing the formation of $\mathbf{2 b}$. At high $\mathbf{C D}$ amount, the intramolecular amidation proceeds with lower rate, due to the smaller number of available active sites and the selectivity of $\mathbf{4 b}$ increases. The latter observation shows that the final step of the cascade reaction occurs on the catalyst surface either immediately after the enantioselective hydrogenation-reduction sequence or following the desorption and readsorption of the chiral amino-alcohol. To a similar conclusion pointed the increase of the quinolone selectivity obtained by increasing the catalyst amount. 

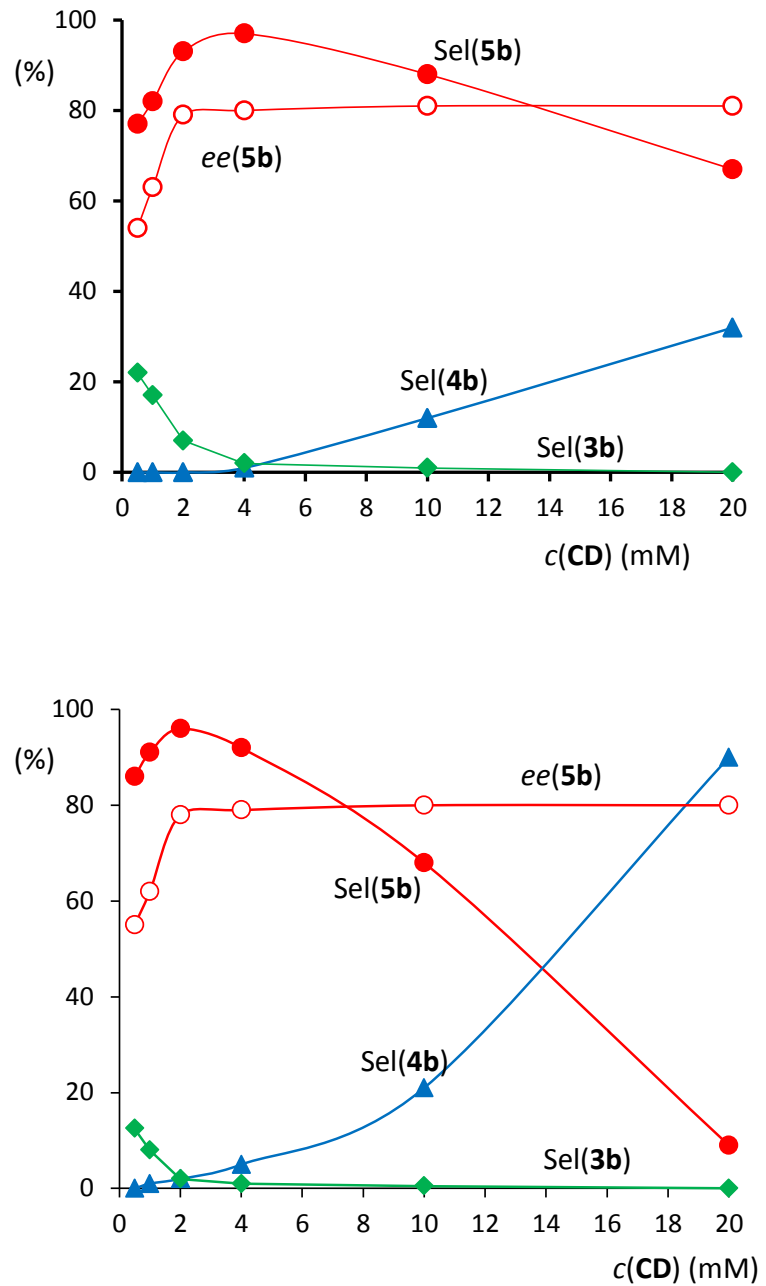

Figure 13. Effect of $\mathrm{CD}$ concentration on the reaction of $\mathbf{1 b}$.

Reaction conditions: $100 \mathrm{mg} \mathrm{Pt} / \mathrm{Al}_{2} \mathrm{O}_{3}, 5 \mathrm{~cm}^{3}$ toluene with 2 vol\% $\mathrm{AcOH}, \mathrm{c}(\mathbf{1 b}) 80 \mathrm{mM}, 1 \mathrm{MPa} \mathrm{H}_{2}$ pressure, $25^{\circ} \mathrm{C}, 2 \mathrm{~h}$, complete conversion of $\mathbf{1 b}$.
Figure 14. Effect of $\mathrm{CD}$ concentration on the reaction of $\mathbf{1 b}$.

Reaction conditions: $50 \mathrm{mg} \mathrm{Pt} / \mathrm{Al}_{2} \mathrm{O}_{3}, 5 \mathrm{~cm}^{3}$ toluene with 2 vol\% AcOH, $c(\mathbf{1 b}) 80 \mathrm{mM}, 1 \mathrm{MPa} \mathrm{H}_{2}$ pressure, $25^{\circ} \mathrm{C}, 3 \mathrm{~h}$, complete conversion of $\mathbf{1 b}$.

Spontaneous cyclization was reported to occur during the enantioselective hydrogenation of 2-oxoglutaric acid over Pt [121]. Data obtained over lower catalyst amounts are presented in Figure 14. These results showed better the tendencies visible in the previous figure, due to amplification of the $\mathbf{C D}$ concentration effect by increasing the modifier/catalyst ratio.

An increase in the modifier coverage by increasing the $\mathbf{C D}$ concentration up to $2 \mathrm{mM}$ caused a shift of the reaction pathway from the partial formation of $\mathbf{3 b}$ to the exclusive formation of $\mathbf{5 b}$, whereas a further increase in the concentration of $\mathbf{C D}$ resulted in a gradual decrease in the hydroquinolone (5b) selectivity and the formation of increasing amounts of amino-alcohol (4b). The ee value also increased up to $2 \mathrm{mM} c(\mathbf{C D})$ followed by constant values upon further increasing the concentration of CD. It should be mentioned that in these experiments the ee of $\mathbf{4 b}$ (not shown in the Figure 14) was always equal or very close to the $e e$ of $\mathbf{5 b}$. Based on these results one may reach to the conclusion that the presence of $\mathbf{C D}$ 
hindered the fast reduction of the nitro group and the formation of indole. However, the adsorbed modifier also hindered the cyclization step over a certain CD concentration. Although, one may speculate that this could occur due to alterations in the adsorption mode of the cinchona alkaloids as a function of coverage [122-124], the most plausible explanation is that for the adsorption of the intermediate product $\mathbf{4 b}$ in order to obtain $\mathbf{5 b}$, the surface of the metal should be only partially covered by the modifier. This confirms that it is highly probable that cyclization occurs on the metal surface, as was suggested previously.

\subsubsection{Effect of the substrate concentration and structure}

The effect of the 2-nitrophenylpyruvate $\mathbf{1 b}$ concentration on the product selectivities and the $e e$ of $\mathbf{5 b}$ is presented in Figure 15.

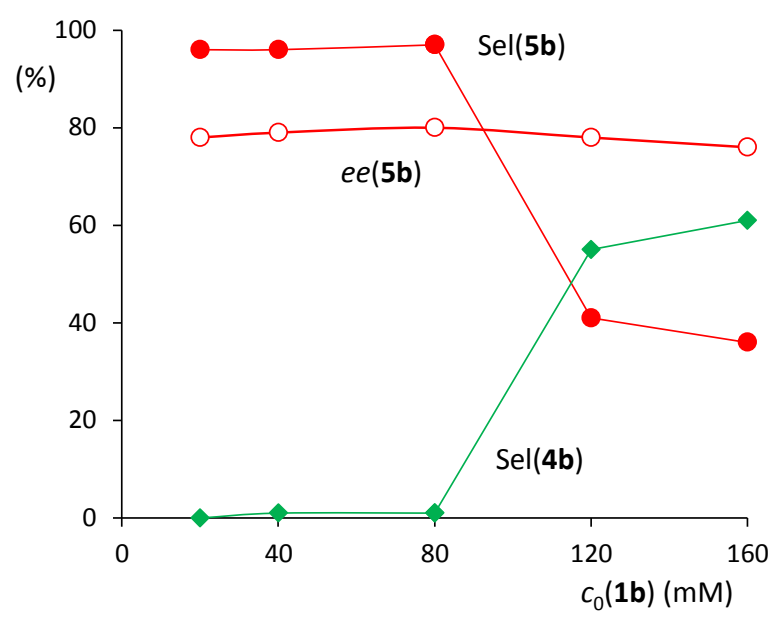

Figure 15. Effect of $\mathbf{1 b}$ initial concentration on the reaction

Reaction conditions: $100 \mathrm{mg} \mathrm{Pt} / \mathrm{Al}_{2} \mathrm{O}_{3}, 5 \mathrm{~cm}^{3}$ toluene with 2 vol\% AcOH, $c(\mathrm{CD}) 4 \mathrm{mM}, 1 \mathrm{MPa} \mathrm{H}$ pressure, $25^{\circ} \mathrm{C}, 2 \mathrm{~h}$, complete conversion of $\mathbf{1 b}$.

Up to $80 \mathrm{mM} c_{0}(\mathbf{1 b})$ an almost exclusive formation of hydroquinolone was detected, however, over this concentration cyclization was not complete and the intermediate $\mathbf{4 b}$ was also detected in the product mixture. As the reduction steps were complete in these experiments, even when the highest $c_{0}(\mathbf{1 b})$ was used, product selectivities were governed by the cyclization rate of amino-alcohol $\mathbf{4 b}$. Thus, under these conditions, the enantioselective hydrogenation and the reduction of the nitro group, the first two steps of the cascade, occurred without desorption of partially reduced intermediates even at a ratio of $8 \mathrm{mmol}$ of substrate per gram of catalyst (corresponding to the highest initial concentration used in our experiments). The decrease in $\mathbf{5 b}$ selectivity over a certain $c_{0}(\mathbf{1 b})(80 \mathrm{mM})$ showed that the cyclization rate was not influenced significantly by the $c_{0}(\mathbf{1 b})$ and longer reaction times are necessary for the complete transformation of larger amounts of $\mathbf{4 b}$ to $\mathbf{5 b}$. 
The 3-methyl-substituted ethyl 2-nitrophenylpyruvate (1b) was chosen as test substrate for these examinations on the basis of results obtained over unmodified Pt [33] and our preliminary experiments. The 3-methyl substituent was suggested to hinder to some extent the reduction of the nitro group, which altered the ratio of the $-\mathrm{C}=\mathrm{O}$ hydrogenation/ $-\mathrm{NO}_{2}$ group reduction rates. Accordingly, the position of the methyl substituent may affect the reactivity of the functional groups, especially that of the $-\mathrm{NO}_{2}$ group bonded to the phenyl ring, by change the adsorption strength and mode of the substrate to the metal surface. This was the reason of carrying out a study on the influence of the position of the methyl substituent, evidenced by comparison of results obtained under identical conditions in the reaction of the three methyl derivatives $(\mathbf{1 b}, \mathbf{1 c}, \mathbf{1 d})$ and the compound lacking a methyl substituent on the phenyl ring (1a). Results obtained are summarized in Table 3.

Table 3. Influence of the methy substituent position on the asymmetric cascade reaction of 2-nitrophenylpyruvates. ${ }^{[\mathrm{a}]}$

Entry Substrate

[a] Reaction conditions: $100 \mathrm{mg} \mathrm{Pt} / \mathrm{Al}_{2} \mathrm{O}_{3}, 5 \mathrm{~cm}^{3}$ toluene with 2 vol\% AcOH, $c(\mathrm{CD}) 4 \mathrm{mM}, c_{0}(\mathbf{1 a}-\mathbf{1 d}) 80 \mathrm{mM}, 1 \mathrm{MPa}$ $\mathrm{H}_{2}$ pressure, $25^{\circ} \mathrm{C}, 2 \mathrm{~h}$, complete transformation of $\mathbf{1 a}-\mathbf{1 d}$. Results are given in (\%).

Variations in the amount of indole derivatives (3a-3d) formed during the reactions may be considered as an indication of the effect of the substituent on the reduction rate of the $-\mathrm{NO}_{2}$ group, considering that the methyl substituent has less effect on the rate of the enantioselective hydrogenation of the $-\mathrm{C}=\mathrm{O}$ group. Accordingly, the data showed that the 3methyl substituent decelerated the reduction of the $-\mathrm{NO}_{2}$ group, whereas the substituent in 
position 5 has no influence when compared with the non-substituted compound 1a. On the contrary, the methyl substituent in position 6 increased the selectivity for 3d. This may be explained by tilting of the adsorbed substrate on the metal due to steric repulsions between the methyl group and the surface, thus allowing easier interaction of the $-\mathrm{NO}_{2}$ group with the $\mathrm{Pt}$ and the chemisorbed hydrogen in the case of substrate 1d. The selectivities for the hydroquinolone derivatives (5a-5d) increased in the presence of the methyl substituent in positions 5 or 3 ; in the case of the latter, an almost exclusive formation of the target product was obtained. Only in the reaction of the compound substituted in position 6 the amount of hydroquinolone $\mathbf{5 d}$ decreased. It must be noted that very similar $e e$ values were obtained with the exception of the reaction of 1c, which may be ascribed to possible hindering of the CDsubstrate interaction on the surface by the methyl group in this position. However, this assumption and the way the substituent in this later position influences the modifier-substrate interaction must be determined by addition, future studies. One can also observe that under these conditions only the reaction of $\mathbf{1 d}$ resulted in a significant amount of reduced uncycled product (4d). A possible explanation of this effect is that the methyl group only in this position hindered the re-adsorption of the amino-alcohol intermediate, which also confirmed the previous suggestion that the cyclization also occurs on the metal surface.

Further the scope of this enantioselective heterogeneous cascade reaction was investigated using a larger series of 2-nitrophenylpyruvate derivatives, which included besides the previously studied methyl substituted compounds, also some alkoxy and fluorine substituted derivatives. As this time the scope of the experiments was to evidence the scope of the reaction, the measurements were carried out using the most efficient modifiers and under several reaction conditions. The best results obtained in the experiments of each compound are summarized in Table 4.

With the exception of compounds substituted on the phenyl ring in the position 5 (5f and 5i), 3-hydroxy-3,4-dihydroquinolin-2(1H)-one derivatives were prepared in good ee values. The best optical purities were obtained in reactions of 2-nitrophenylpyruvates with the phenyl ring substituted in positions 3 and $6(88-90 \% e e)$, however substituents in position 6 decreased the hydroquinolone yield (see entries 4 and 10). The effect of the substituent position on the hydroquinolone yield was explained by the steric effect of these substituents, namely their influence on the reduction rate of the nitro group. However, the anchoring effect of the substituents, i.e. their interaction with the surface may also be partially responsible for the obtained results. Lower yields were obtained generally with the fluorine substituted derivatives, which may be explained by such anchoring effect. 


\begin{tabular}{|c|c|c|c|c|c|}
\hline \multirow[b]{2}{*}{ Entry } & \multirow{2}{*}{ Substrate } & \multirow[t]{2}{*}{$\overbrace{\mathrm{NO}_{2}^{\mathrm{O}}}^{\mathrm{T}}$} & \multirow{2}{*}{$\begin{array}{l}\text { OOOEt } \begin{array}{c}+1 \mathrm{MPa} \mathrm{H}{ }_{2}, \mathrm{Pt}_{\mathrm{Al}} \mathrm{O}_{3} \\
\text { modifier, } \mathrm{T} / \mathrm{AcOH}\end{array} \\
\stackrel{-\mathrm{EtOH}}{\longrightarrow}\end{array}$} & \multirow{2}{*}{$\frac{\text { Yield }(5)^{[b]}}{\left.{ }^{[b}\right)}$} & \multirow[b]{2}{*}{$e e(5)(R$} \\
\hline & & & & & \\
\hline 1. & $1 a$ & $\mathrm{H}$ & $50 \mathrm{mg} \mathrm{Pt} / \mathrm{Al}_{2} \mathrm{O}_{3}, \mathrm{~T}+10 \mathrm{vol} \% \mathrm{AcOH}$ & 65 & 90 \\
\hline 2. & $1 b$ & 3-Me & $100 \mathrm{mg} \mathrm{Pt} / \mathrm{Al}_{2} \mathrm{O}_{3}, \mathrm{~T}+2 \mathrm{vol} \% \mathrm{AcOH}$ & 97 & 90 \\
\hline 3. & $1 c$ & 5-Me & $50 \mathrm{mg} \mathrm{Pt} / \mathrm{Al}_{2} \mathrm{O}_{3}, \mathrm{~T}+10 \mathrm{vol} \% \mathrm{AcOH}$ & 88 & 86 \\
\hline 4. & $1 d$ & 6-Me & $50 \mathrm{mg} \mathrm{Pt} / \mathrm{Al}_{2} \mathrm{O}_{3}, \mathrm{~T}+10 \mathrm{vol} \% \mathrm{AcOH}$ & 55 & 89 \\
\hline 5. & $1 e$ & 3-OMe & $50 \mathrm{mg} \mathrm{Pt} / \mathrm{Al}_{2} \mathrm{O}_{3}, \mathrm{~T}+10 \mathrm{vol} \% \mathrm{AcOH}$ & 97 & 88 \\
\hline 6. & $1 f$ & 5-OMe & $50 \mathrm{mg} \mathrm{Pt} / \mathrm{Al}_{2} \mathrm{O}_{3}, \mathrm{~T}+10 \mathrm{vol} \% \mathrm{AcOH}$ & 75 & 69 \\
\hline 7. & $1 g$ & 3-O'Pr & $100 \mathrm{mg} \mathrm{Pt} / \mathrm{Al}_{2} \mathrm{O}_{3}, \mathrm{~T}+2 \mathrm{vol} \% \mathrm{AcOH}$ & 97 & 85 \\
\hline 8. & $1 \mathrm{~h}$ & $4-\mathrm{F}$ & $50 \mathrm{mg} \mathrm{Pt} / \mathrm{Al}_{2} \mathrm{O}_{3}, \mathrm{~T}+10$ vol\% $\mathrm{AcOH}$ & 50 & 82 \\
\hline 9. & $\mathbf{1 i}$ & $5-F$ & $100 \mathrm{mg} \mathrm{Pt} / \mathrm{Al}_{2} \mathrm{O}_{3}, \mathrm{~T}+10 \mathrm{vol} \% \mathrm{AcOH}^{[\mathrm{c}]}$ & 55 & 68 \\
\hline 10. & $1 \mathbf{j}$ & $6-\mathrm{F}$ & $100 \mathrm{mg} \mathrm{Pt} / \mathrm{Al}_{2} \mathrm{O}_{3}, \mathrm{~T}+10 \mathrm{vol} \% \mathrm{AcOH}^{[\mathrm{c}]}$ & 35 & 90 \\
\hline
\end{tabular}

\subsubsection{Reaction pathways in the asymmetric heterogeneous catalytic cascade}

According to the results of racemic reaction published by Murakami and co-workers it is known that the cascade reaction studied here starts with the competitive hydrogenation of the keto and nitro groups. For obtaining hydroquinolone derivative the activated keto group is hydrogenated before or at least simultaneously with the reduction of the nitro group. The initial either partial or complete reduction of the nitro group leads to concomitant intramolecular cyclization by condensation with the keto group and formation of hydroxylindole or indole derivative. Hence, the formation of the hydroquinolone derivative is possible only if the keto group is not available, that is, is already transformed, by the time when the nitro group reduction occurs.

The method developed by us using Pt catalysts modified by cinchona alkaloids was efficient due to influencing the rates of the enantioselective hydrogenation and of the aromatic nitro group reduction by modification of the Pt surface. Accordingly, the presence of the modifier had double effect on the hydrogenation of 2-nitrophenylpyruvates, that is, induced 
enantioselectivity and increased the selectivity of the hydroquinolone by accelerating the ketone hydrogenation concomitantly with decreasing the reduction rate of the nitro group. Fortunately, the enantioselection was also improved in the cascade reactions, possibly by participation of the nitro group in the interaction of the 2-nitrophenylpyruvates with the surface chiral site, as shown by the much higher ee obtained in these reactions as compared with the phenylpyruvic acid ethyl ester (up to $38 \%$ ee under identical conditions using CD modifier). A further important aspect of the reaction over the modified catalyst is that all three steps are taking place on the Pt surface, i.e. the final cyclization step of the cascade reaction also occurs on the metal surface. According to these interpretations the possible reaction pathways leading to the formation of the desired product and the side-products are shown in Scheme 16.

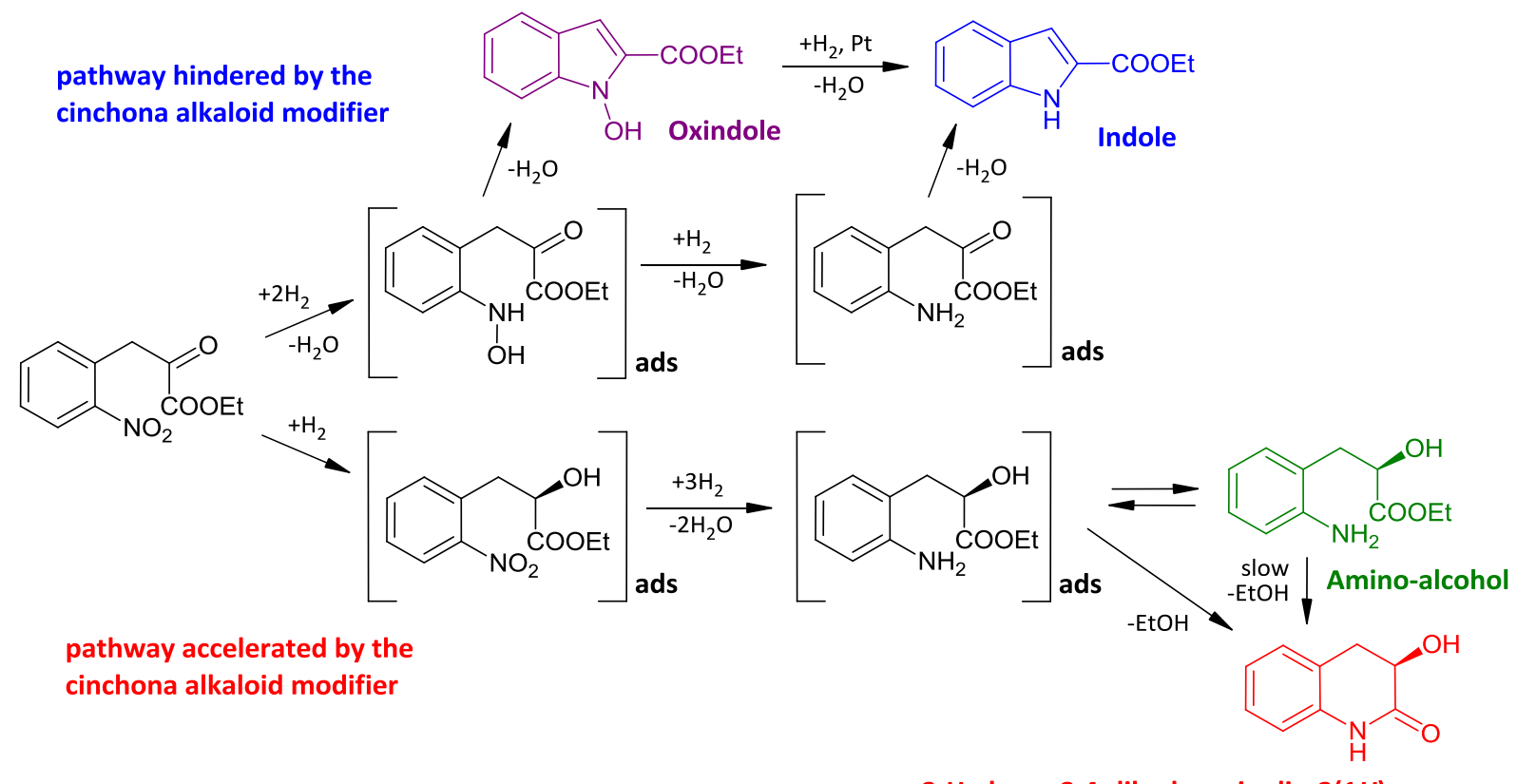

3-Hydroxy-3,4-dihydroquinolin-2(1H)-one

Scheme 16. Reaction pathways in the developed asymmetric cascade reaction. 


\subsection{Hydrogenation of 2-nitrophenylpyruvates in continuous flow system}

Encouraged by numerous reports on successful enantioselective hydrogenations in continuous-flow systems over modified catalysts [70-72,80,125,126], next we investigated the developed asymmetric heterogeneous catalytic cascade reaction of 2-nitrophenylpyruvates to optically enriched 3-hydroxy-3,4-dihydroquinolin-2(1H)-ones in a continuous-flow system under flow conditions using a fixed-bed reactor. It is known that studies in continuous-flow systems may help identifying the elementary steps of catalytic reactions [127]. Accordingly, we also attempted to obtain new mechanistic details or confirmation of the suggestions based on batch experiments using a flow system. Clarifying unknown mechanistic aspects of the reaction may open the possibility of developing other efficient asymmetric catalytic cascades.

The reaction was studied using $\mathrm{H}-\mathrm{Cube}^{\circledR}$ continuous-flow hydrogenation system presented in Figure 8 [107]. This experimental set-up allows mixing the $\mathrm{H}_{2}$ gas with the solution of the reactant and modifier under a system pressure set by a back-pressure regulator and passing the mixture through a catalyst bed. The system previously was thoroughly tested in enantioselective hydrogenations over chirally modified metal catalysts in our research group $[71,80,125,126]$.

\subsubsection{Effect of reaction conditions}

Initial results obtained in the flow system using $\mathbf{1 b}$ as substrate are shown in Figure 16. The reaction was carried out using the solvent mixture, $\mathrm{H}_{2}$ pressure, temperature, modifier and substrate concentrations found appropriate for obtaining high conversions and excellent 5b selectivities in batch experiments. However, in contrast to results obtained in batch system, under flow conditions only low $(\approx 20 \%)$ conversions were obtained. The lack of $\mathbf{3 b}$ formation indicated that the hydrogenation of the keto group was faster than that of the nitro group under these conditions in the flow system, too. However, very low $\mathbf{5 b}$ selectivities were obtained, the main product was the amino-alcohol $\mathbf{4 b}$. This confirmed that the final cyclization step of the cascade occurs only at higher conversions of $\mathbf{1 b}$, which was interpreted by desorption and re-adsorption of $\mathbf{4 b}$ based on the results obtained in batch experiments. The enantioselectivity of the keto group hydrogenation, i.e. the ee of $\mathbf{4 b}$, was much lower as in batch system (slightly less than 60\%). 


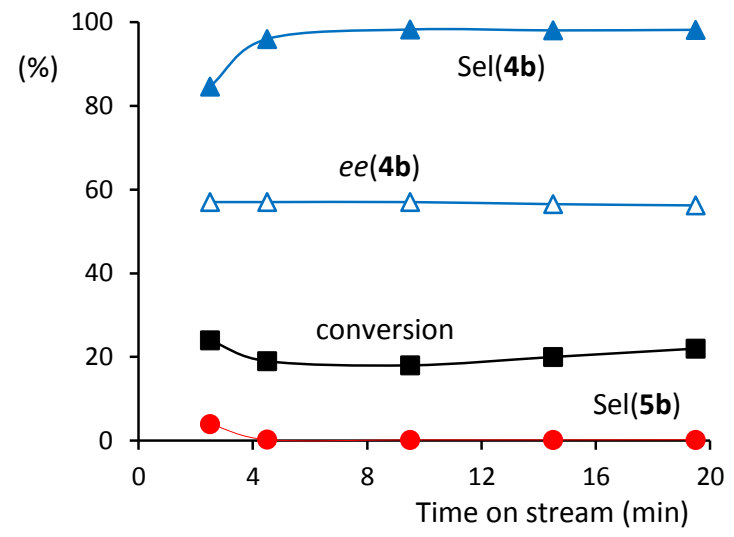

Figure 16. Reaction of $\mathbf{1 b}$ in $\mathrm{H}$-Cube ${ }^{\circledR}$ continuousflow system.

Reaction conditions: $375 \mathrm{mg} \mathrm{Pt} / \mathrm{Al}_{2} \mathrm{O}_{3}$ prehydrogenated in $0.5 \mathrm{~cm}^{3} / \mathrm{min}$ toluene under $1 \mathrm{MPa} \mathrm{H}_{2}$ pressure 30 min; reaction in toluene with 2 vol\% $\mathrm{AcOH}, \mathrm{c}(\mathrm{CD}) 4 \mathrm{mM}$, $c_{0}(\mathbf{1 b}) 80 \mathrm{mM}, 1 \mathrm{MPa} \mathrm{H}_{2}$ pressure, flow rate 0.5 $\mathrm{cm}^{3} / \mathrm{min}, 25^{\circ} \mathrm{C}$.

According to these results the reaction conditions in flow system have to be changed for obtaining higher conversions, which could be accompanied by higher $\mathbf{5 b}$ selectivities, while keeping the rate of the nitro group reduction low, to avoid formation of the indole derivative $\mathbf{3 b}$. Hence, we have studied the effect of reaction conditions, found to be crucial in batch experiments such as the $\mathrm{H}_{2}$ pressure, substrate and modifier concentrations and also the effect of parameters specific for the flow systems such as the flow rate and recirculation of the product solution. As decrease of the reaction temperature had detrimental effect on the cyclization step (resulting in formation of $\mathbf{4 b}$ instead of $\mathbf{5 b}$ ) even in batch system and increase of the temperature could result in deteriorated $e e$ values due to possible transformation of $\mathbf{C D}$ in less efficient derivatives $[118,128]$, all the following studies were carried out at room temperature. The effect of the $\mathrm{H}_{2}$ pressure is shown in Figure 17. In this experiment the flow rate and the concentration of $\mathbf{1 b}$ was also lower as compared with the previous experiment, which could help to obtain higher conversions and presumably higher $\mathbf{5 b}$ selectivities.

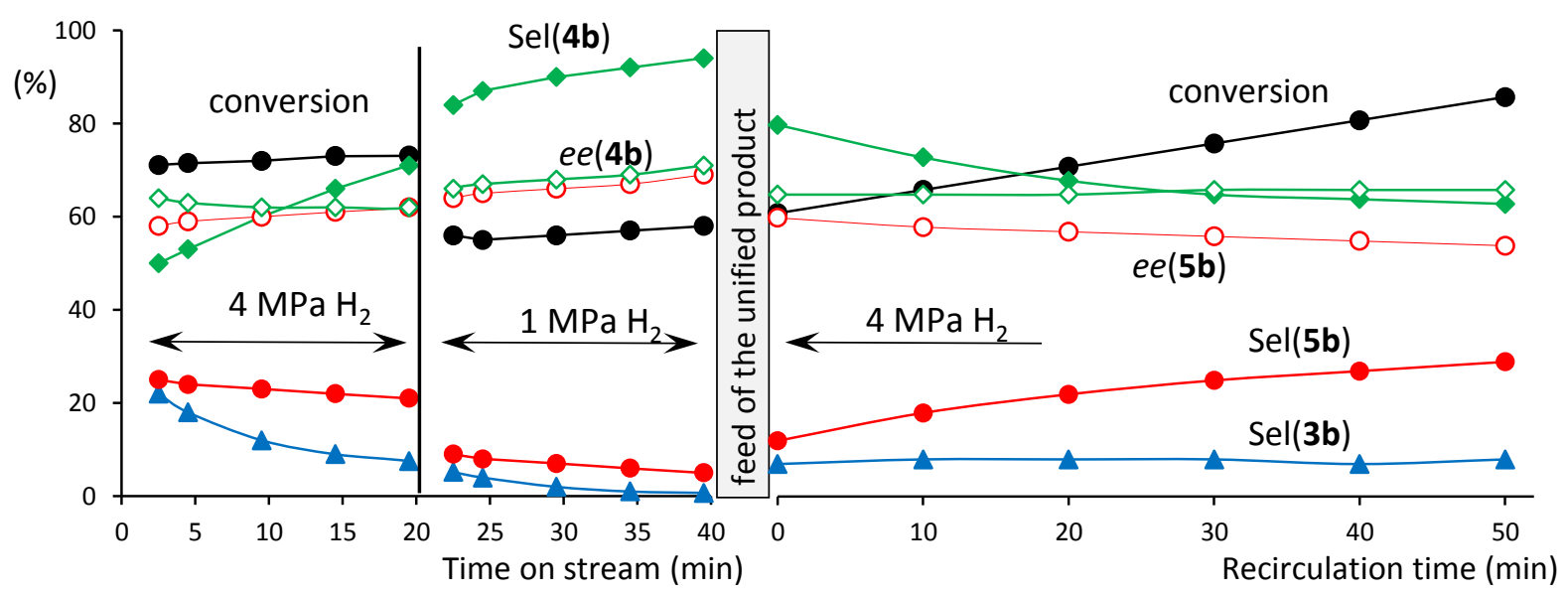

Figure 17. Hydrogen pressure effect and results obtained by recirculation of the product mixture in $\mathrm{H}$-Cube ${ }^{\circledR}$ system.

Reaction conditions: $360 \mathrm{mg} \mathrm{Pt} / \mathrm{Al}_{2} \mathrm{O}_{3}$ pre-hydrogenated in $0.3 \mathrm{~cm}^{3} / \mathrm{min}$ toluene under 4 $\mathrm{MPa} \mathrm{H}_{2}$ pressure $30 \mathrm{~min}$; reaction in toluene with 2 vol\% $\mathrm{AcOH}, \mathrm{c}(\mathrm{CD}) 4 \mathrm{mM}, \mathrm{c}_{0}$ (1) 27 $\mathrm{mM}, 1 \mathrm{MPa} \mathrm{H}_{2}$ pressure, flow rate $0.3 \mathrm{~cm}^{3} / \mathrm{min}, 25^{\circ} \mathrm{C}$. 
Under these conditions the conversion could be increased to over $70 \%$ under $4 \mathrm{MPa}$ $\mathrm{H}_{2}$ pressure, which resulted in over $20 \% \mathbf{5 b}$ selectivity. Unfortunately, under these conditions the $\mathbf{3 b}$ selectivity also increased, though this value decreased during time on stream concomitantly with increase in $\mathbf{4 b}$ selectivity. Thus, a change in the relative rates of the two reduction steps occurred during time on stream in favour of the enantioselective hydrogenation, which could be due to loss in activity or decrease in the number of active sites responsible for the reduction of the nitro group. The close to constant enantioselectivity of the formation of both chiral products $(\mathbf{4 b}$ and $\mathbf{5 b}$ ) hardly exceeded $60 \%$. Although, decreasing the $\mathrm{H}_{2}$ pressure to $1 \mathrm{MPa}$ increased the ee up to $70 \%$, both the conversion and the selectivity of $\mathbf{5 b}$ decreased. Because no full conversion and relatively low $\mathbf{5 b}$ selectivities were reached by passing once the solution of the substrate through the catalyst bed, the resulting product mixture was continuously recirculated over the catalyst (the supplier and collector was the same vessel) under $4 \mathrm{MPa} \mathrm{H}_{2}$ pressure and the solution was analysed.

During the recirculation (see Figure 17) besides increase in the conversion to over $85 \%$ the selectivity of $\mathbf{4 b}$ slightly decreased and that of $\mathbf{5 b}$ increased. However, the increase of the latter didn't exceed the observed conversion increase. Accordingly, even if the conversion was relatively high the transformation of the desorbed $\mathbf{4 b}$ to $\mathbf{5 b}$ didn't occur, the formation of $\mathbf{5 b}$ was probably due to instantaneous cyclization over the metal surface without desorption of the reduced intermediate $\mathbf{4 b}$. This could be the consequence of the progressively decreasing $\mathbf{1 b}$ concentration in the solution. As effect $\mathbf{1 b}$ couldn't replace the adsorbed surface products at such a rate as at the beginning of the reaction. However, the significant amount of $\mathbf{4 b}$ accumulated earlier in the product mixture confirmed our earlier proposal that 5b is formed mainly by desorption - re-adsorption pathway on the Pt surface following complete consumption of $\mathbf{1 b}$ and in smaller part directly without desorption of the intermediate. We presume that the extent on which the instantaneous cyclization occurs depends greatly on the reaction conditions. As the optimal conditions differ in batch and continuous-flow system, it is understandable that in these two kinds of systems the two pathways may contribute in different extent to the formation of $\mathbf{5 b}$.

During the recirculation small decrease in the ee of $\mathbf{5 b}$ was also observed. The most plausible reason of the ee decrease is the alteration of the enantio-differentiation ability of the chiral surface, as a consequence of the transformation of $\mathbf{C D}$ by partial hydrogenation of the quinoline moiety. This observation also answers the question what would happen if the modifier feed is stopped, i.e. the ee would decrease gradually as the adsorbed modifier is 
transformed. However, beside a probable decrease in the ee, deterioration of the selectivities are also expected to occur based on the multiple role of the cinchona modifier.

\subsubsection{Reactions over catalyst pre-modified by cinchonidine}

Next we tried to improve the results obtained in the flow system by pre-modifying the catalyst with $\mathrm{CD}$ and using lower modifier concentration during the reaction, as the presence of excess modifier during the reaction may also hinder the cyclization step. The solvent composition was changed to toluene with $10 \mathrm{vol} \% \mathrm{AcOH}$ during these experiments, whereas the flow rate and the substrate concentration was further decreased. Representative results are shown in Figure 18. Indeed, under such conditions high, over 90\% conversions and around $40 \% \mathbf{5 b}$ selectivities were reached. However, the formation of high amounts of $\mathbf{3 b}$ was also detected.

(\%)

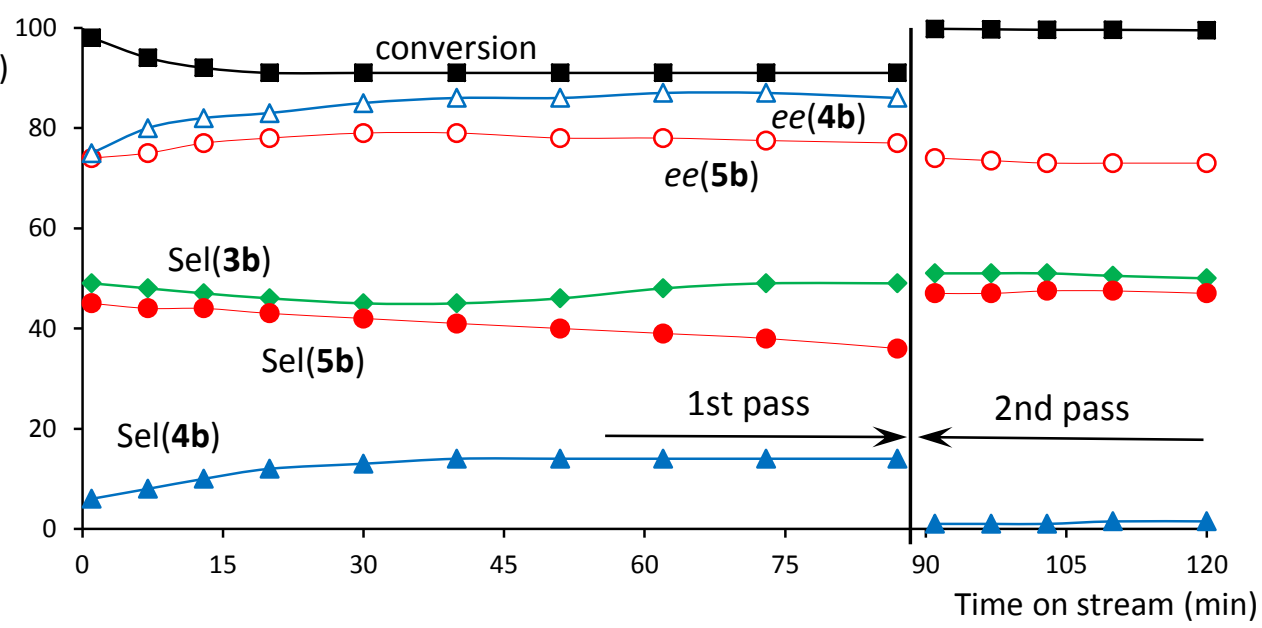

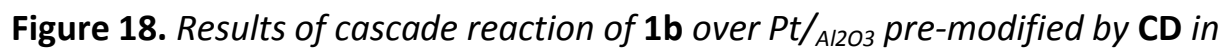
H-Cube ${ }^{\circledast}$ system.

Reaction conditions: $365 \mathrm{mg} \mathrm{Pt} / \mathrm{Al}_{2} \mathrm{O}_{3}$ prehydrogenated in $0.2 \mathrm{~cm}^{3} / \mathrm{min}$ toluene under 4 $\mathrm{MPa} \mathrm{H}_{2}$ pressure 30 min followed by pre-modification with $\mathrm{CD}$ solution in tolune with 10 vol\% AcOH, $c(C D) 5 \mathrm{mM}$, flow rate $0.2 \mathrm{~cm}^{3} / \mathrm{min}, 4 \mathrm{MPa} \mathrm{H}_{2}$ pressure, $30 \mathrm{~min}$; reaction in toluene with 10 vol\% $\mathrm{AcOH}, c(\mathbf{C D}) 1 \mathrm{mM}, c_{0}$ (1) $20 \mathrm{mM}, 4 \mathrm{MPa} \mathrm{H}_{2}$ pressure, flow rate 0.2 $\mathrm{cm}^{3} / \mathrm{min}, 25^{\circ} \mathrm{C}$.

Passing the product solution for the second time over the catalyst bed led to almost complete disappearance of $\mathbf{1 b}$ and $\mathbf{4 b}$ from the mixture, resulting practically in a 1/1 mixture of $\mathbf{5 b}$ and $\mathbf{3 b}$. Increase in the enantioselectivity, as compared with the previously shown results was also observed, however, the difference in the $e e$ of $\mathbf{4 b}$ and $\mathbf{5 b}$ indicated that kinetic resolution may occur during the cyclization step, which confirmed the involvement of the $\mathrm{Pt}$ 
surface in this final step. The second passage of the mixture increased the $\mathbf{5 b}$ selectivity together with slightly decreasing the ee of this compound. Thus, this experiment clearly showed that at complete conversion of $\mathbf{1 b}$ the desorbed $\mathbf{4 b}$ is transformed to $\mathbf{5 b}$. The ee decrease may be explained as discussed in the previous subsection, i.e. by the transformation of CD. However, the above suggested racemization during cyclization may also be a plausible explanation of this ee decrease, which as mentioned, would be a confirmation of the surface cyclization step.

Finally, selected results of our attempts to improve the yield and optical purity of the quinolone derivative $\mathbf{5 b}$ by further changing the reaction conditions are summarized in Table 5. The substrate concentration was kept at the value used in the previous experiment, as this concentration already allowed high conversions and low $\mathbf{4 b}$ selectivities. Based on results obtained in batch system decrease under a certain value of the substrate concentration had no effect on the $\mathbf{5 b}$ selectivity and ee. However, under flow conditions such change could lead to increase in $\mathbf{3 b}$ selectivity, as shown by the relatively high $\mathbf{3 b}$ amount obtained in the experiment shown in Figure 18.

\begin{tabular}{|c|c|c|c|c|c|c|c|c|}
\hline Entry & $\begin{array}{l}\text { Flow } \\
\text { rate }^{[b]}\end{array}$ & $\begin{array}{l}c(\mathrm{CD}) \\
(\mathrm{mM})\end{array}$ & $\begin{array}{l}p \mathrm{H}_{2} \\
(\mathrm{MPa})\end{array}$ & $\begin{array}{l}\text { Conv. } \\
(\%)^{[c]}\end{array}$ & $\begin{array}{l}\text { Sel(4b), } \\
\text { ee(4b) (\%) }\end{array}$ & $\begin{array}{l}\text { Sel(3b) } \\
(\%)\end{array}$ & $\begin{array}{l}\text { Sel(5b), } \\
\text { ee(5b) (\%) }\end{array}$ & $\begin{array}{l}\text { Yield(5b) } \\
(\text { mmol) })^{[d]}\end{array}$ \\
\hline 1. & 0.2 & 1 & 4 & $91 \pm 2$ & $13 \pm 2,85$ & $46 \pm 3$ & $43 \pm 2,77$ & 0.18 \\
\hline $2 .^{[\mathrm{e}]}$ & 0.2 & 1 & 4 & $92 \pm 2$ & $10 \pm 2,80$ & $50 \pm 3$ & $38 \pm 2,68$ & 0.16 \\
\hline 3. & 0.2 & 2 & 4 & $88 \pm 2$ & $30 \pm 2,81$ & $34 \pm 3$ & $36 \pm 2,72$ & 0.15 \\
\hline 4. & 0.1 & 2 & 4 & $94 \pm 2$ & $17 \pm 3,80$ & $40 \pm 2$ & $43 \pm 2,72$ & 0.09 \\
\hline 5. & 0.2 & 2 & 6 & $98 \pm 1$ & $4 \pm 1,78$ & $46 \pm 2$ & $49 \pm 2,73$ & 0.22 \\
\hline 6. & 0.5 & 2 & 6 & $80 \pm 2$ & $45 \pm 2,80$ & $30 \pm 2$ & $23 \pm 2,72$ & 0.22 \\
\hline $7 .^{[f]}$ & - & 4 & 1 & 100 & $\leq 1$ & 2 & $97 \pm 1,80$ & 0.38 \\
\hline
\end{tabular}

\footnotetext{
${ }^{\text {[a] }}$ Catalyst: $360 \pm 20 \mathrm{mg} \mathrm{Pt} / \mathrm{Al}_{2} \mathrm{O}_{3}$, pre-hydrogenation in toluene under the given $\mathrm{H}_{2}$ pressure 30 min followed by pretreatment with $5 \mathrm{mM}$ CD solution in toluene with 10 vol\% AcOH for 30 min using the given flow rate and $\mathrm{H}_{2}$ pressure. Reaction conditions: toluene with $10 \mathrm{vol} \% \mathrm{AcOH}, c_{0}(\mathbf{1 b}) 20 \mathrm{mM}$, room temperature, results obtained after 30 min time on stream.

${ }^{[b]}$ Flow rate in $\mathrm{cm}^{3} / \mathrm{min}$. ${ }^{[c]}$ Conversion. [d] Yield of $\mathbf{5 b}$ obtained in $2 \mathrm{~h} .{ }^{[\mathrm{e}]}$ reaction in Toluene with 20 vol\% $\mathrm{AcOH}$.

${ }^{[\mathrm{ff}]}$ Results obtained in batch system.
}

Although high conversions were reached in most of these attempts summarized in Table 5, the products contained high amounts of side-products such as $\mathbf{4 b}$ and $\mathbf{3 b}$, unlike in the reaction carried out in batch reactor (entry 7). Thus, one of the most significant advantage 
of using heterogeneous catalyst in a flow system was diminished as the hydroquinolone derivative $\mathbf{5 b}$ had to be purified by flash chromatography, unlike using batch setup, where this product was obtained in satisfactory purity following the removal the modifier and solvent. Due to the low hydroquinolone selectivity, the yield of $\mathbf{5 b}$ obtained in $2 \mathrm{~h}$ operation in continuous-flow system (the same reaction time as used in the batch experiment) was always lower than in batch system, though by increasing the selectivity it would be possible to outperform the latter. Moreover, the enantioselectivities were also below those obtained in batch system using the same modifier. Interestingly, the enantioselectivity of the aminohydroxyester $\mathbf{4 b}$ was higher in all these experiments as compared with $\mathbf{5 b}$, which indicated a slight kinetic resolution during cyclization, unlike in batch system. Although, presently the continuous-flow system was proved to be less appropriate to carry out this reaction, we cannot exclude that further improvements will be reached both in the enantioselectivity and the yield of the desired hydroquinolone $\mathbf{5 b}$ either by tuning the reaction condition or by designing special catalysts for use under flow conditions.

In conclusion we developed the first heterogeneous catalytic asymmetric cascade reaction for the efficient synthesis of hydroquinolone derivatives starting from 2nitrophenylpyruvates in high yields and good enantioselectivities. Finally, the heterogeneous cascade reaction disclosed here is a novel application of the Orito reaction and could also be a starting point for developing attractive strategies for the synthesis of various optically pure Nheterocyclic compounds. 


\section{SUMMARY}

We have developed a novel method for the enantioselective preparation of chiral hydroquinolone derivatives using supported Pt catalysts modified by cinchona alkaloids. The asymmetric heterogeneous catalytic cascade reaction of a 2-nitrophenylpyruvate derivatives afforded $(R)$-3-hydroxy-3,4-dihydroquinolin-2(1H)-one derivatives in good yields and high enantioselectivities when cinchonidine or its methyl ethers were used as chiral modifier. It was shown that the cascade leading to these products started with the enantioselective hydrogenation of the activated keto group, followed by the reduction of the nitro group and finally the intramolecular amidation, all three steps occurring on the Pt surface, according to Scheme 17.

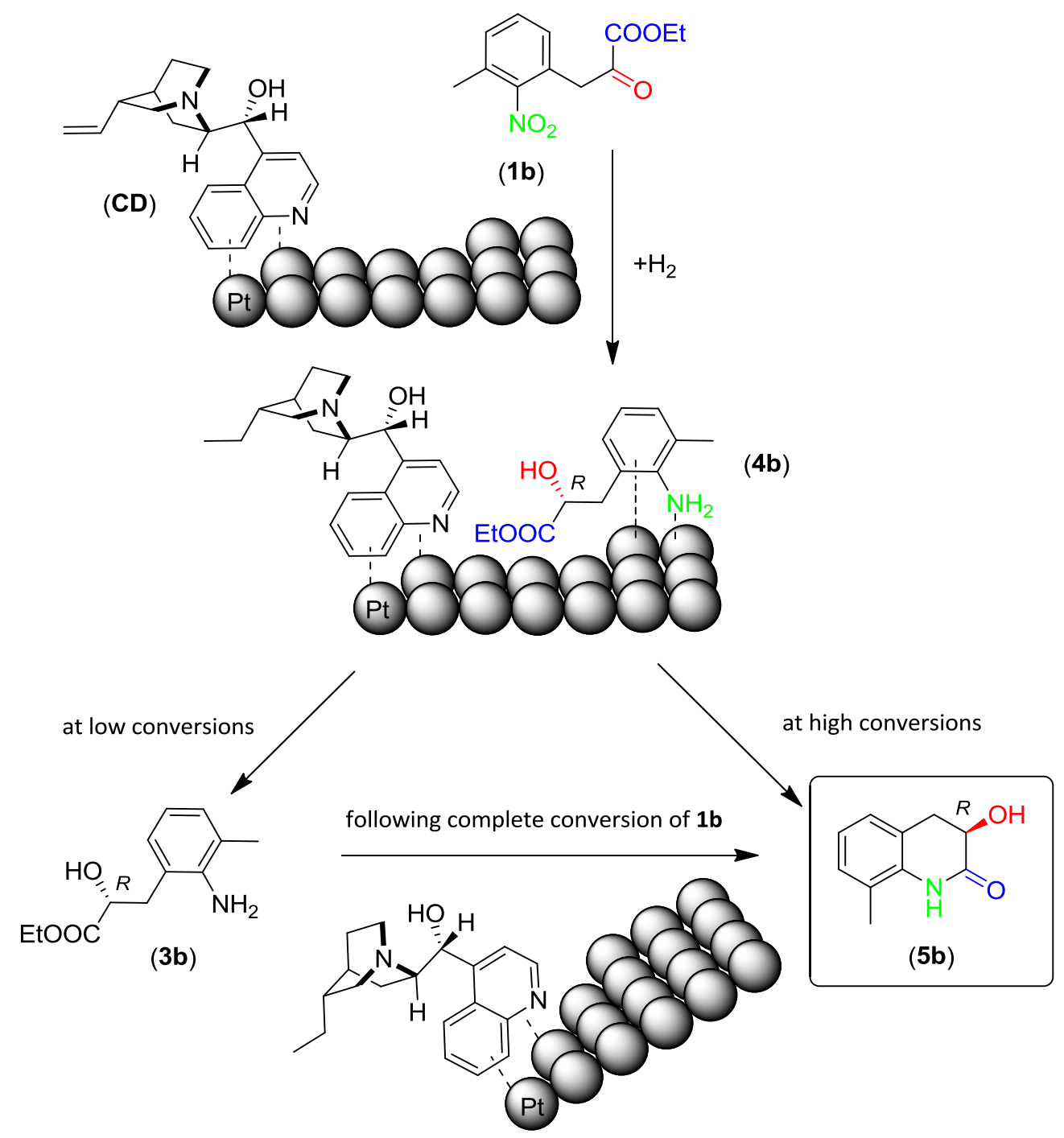

Scheme 17. Steps of the studied asymmetric heterogeneous catalytic reaction. 
This method is based on influencing the rates of the two competitive steps, the enantioselective hydrogenation of the activated keto group and the aromatic nitro group reduction. According to the Reissert indole synthesis these compounds provide indole derivatives, which are formed by cyclization of the amino group resulted by reduction of the nitro group and the keto group. However, the main products in our reactions were the corresponding hydrogenated amino-alcohol derivative (4) and the hydroquinolone (5) derivate, according to Scheme 17.

We found that tuning the reaction conditions has a major influence on the product composition, as the enantioselective hydrogenation and the reduction of the nitro group are competing reactions, both catalysed on the Pt surface. Substituents on the aromatic ring have important influence on the hydroquinolone yields, which was explained by their effect on the reduction rate of the nitro group. It was demonstrated, that the final cyclization step of the cascade reaction occurs on the catalyst, i.e. metal surface. The effect of the substrate concentration indicated, that the reaction proceeded without desorption of the partially reduced intermediates between the steps. Results of examining the influence of the catalyst amount indicated that the third and final step of the reaction also proceeded on the catalyst. The latter conclusion was supported by the influence of $\mathrm{H}_{2}$ pressure, modifier and substrate concentrations on the selectivities of the products. The accumulation of the intermediate $\mathbf{4 b}$ in the reaction mixture showed that the cyclization takes place on the Pt surface following desorption and re-adsorption of this intermediate. Eventually, it was concluded that all three steps of this unique cascade reaction, which leads to optically enriched N-heterocyclic compounds, take place on the Pt surface.

We have investigated the possibility of carrying out the reaction in a continuous-flow system using a fixed-bed reactor filled with $\mathrm{Pt} / \mathrm{Al}_{2} \mathrm{O}_{3}$ modified by cinchonidine. However, the high selectivities and enantioselectivities of the main $(R)$-3-hydroxy-3,4-dihydroquinolin2(1H)-one products obtained in batch reactor were not achieved, due to perturbed rate balance of the first two competitive steps. Pre-modification of the $\mathrm{Pt} / \mathrm{Al}_{2} \mathrm{O}_{3}$ catalyst with the cinchona modifier enhanced the product selectivity, whereas recirculation of the product mixture besides increasing the conversion and selectivity, didn't cause a drastic change in $e e$.

This study highlighted, that the heterogeneous cascade reaction disclosed here is a novel application of the Orito reaction and could also be a starting point for developing attractive strategies for the synthesis of various advantageous optically pure N-heterocyclic compounds. 


\section{Acknowledgments}

I am very grateful to my supervisor Professor Dr. Ferenc Fülöp, Head of the Institute of Pharmaceutical Chemistry for his encouragement and the possibility that I was made my Ph.D. work.

I wish to express my warmest thanks to my second supervisor, Dr. György Szőllősi for his scientific guidance of my work, encouragement and useful advices.

I would like to express my thanks to all members of MTA-SZTE Stereochemistry Research Group for their help and encouragement.

I thank the Richter Gedeon Centenáriumi Alapítvány for financial support my Ph.D. study from September 12015 to May 312016.

Finally, I would like to give my special thanks to my family for their love and support. 


\section{References}

[1] Heterocycles in Natural Product Synthesis, (Eds.: K. C. Majumdar, S. K. Chattopadhyay), Wiley-VCH, Weinheim, 2011.

[2] Chiral Drugs Chemistry and Biological Action, (Eds.: G.-Q. Lin, Q.-D. You, J.-F. Cheng), Wiley-VCH, Hoboken, 2011.

[3] A. R. Jagdale, R. S. Reddy, A. Sudalai, Org. Lett. 2009, 11, 803-806.

[4] M. M. Claffey et al., Pfizer Inc., Pat. US 2010/0324043 A1.

[5] R. H. F. Manske, Chem. Rev. 1942, 30, 113-144.

[6] R. Camps, Arch. Pharm. 1901, 239, 591-601.

[7] W. H. Porter, Pure Appl. Chem. 1991, 63, 1119-1122.

[8] Asymmetric Synthesis - The Essentials (Eds.: M. Christmann, S. Bräse) Wiley-VCH, Weinheim, 2007.

[9] Chiral Catalysts Immobilization and Recycling, (Eds.: D. E. De Vos, I. F. J. Vankelecom, P. A. Jacobs), Wiley- $V C H$, Weinheim, 2000.

[10] Handbook of Asymmetric Heterogeneous Catalysis, (Eds.: K. Ding, Y. Uozumi), Wiley-VCH, Weinheim, 2008.

[11] Catalytic Methods in Asymmetric Synthesis. Advanced Materials, Techniques, and Applications, (Eds.: M. Gruttadauria, F. Giacalone), Wiley-VCH, Hoboken, 2011.

[12] V. Sridharan, P. A. Suryavanshi, J. C. Menéndez, Chem. Rev. 2011, 111, 7157-7259.

[13] M. T. Reetz, X. Li, Chem. Commun. 2006, 2159-2160.

[14] N. Mršić, L. Lefort, J. A. F. Boogers, A. J. Minnaard, B. L. Feringa, J. G. de Vries, Adv. Synth. Catal. 2008, 350, 1081-1089.

[15] C. Wang, C. Li, X. Wu, A. Pettman, J. Xiao, Angew. Chem. Int. Ed. 2009, 48, 6524-6528.

[16] F.-R. Gou, W. Li, X. Zhang, Y.- M. Liang, Adv. Synth. Catal. 2010, 352, 2441-2444.

[17] W. Tang, Y. Sun, L. Xu, T. Wang, Q. Fan, K.-H. Lam, A. S. C. Chan, Org. Biomol. Chem. 2010, 8, 3464-3471.

[18] Z. Yu, W. Jin, Q. Jiang, Angew. Chem. Int. Ed. 2012, 51, 6060-6072.

[19] H. Sundén, R. Rios, I. Ibrahem, G.-L. Zhao, L. Eriksson, A. Córdova, Adv. Synth Catal. 2007, 349, 827-832.

[20] M. Xie, X. Chen, Y. Zhu, B. Gao, L. Lin, X. Liu, X. Feng, Angew. Chem. Int. Ed. 2010, 49, 3799-3802.

[21] K. Mori, K. Ehara, K. Kurihara, T. Akiyama, J. Am. Chem. Soc. 2011, 133, 6166-6169.

[22] L. Ren, T. Lei, J.-X. Ye, L.-Z. Gong, Angew. Chem. Int. Ed. 2012, 51, 771-774.

[23] Enantioselective Chemical Synthesis, Methods, Logic, and Practice, (Eds.: E. J. Corey, L. Kürti), Direct Book Publ., Dallas, Texas, 2010.

[24] Y.-G. Zhou, Acc. Chem. Res. 2007, 40, 1357-1366.

[25] T. Yuanfu, D. Jingen, Progress Chem. 2010, 22, 1242-1253.

[26] Asymmetric Organocatalysis, (Eds.: A. Berkessel, H. Groeger), Wiley-VCH, Weinheim, 2005.

[27] H. Pellissier, Tetrahedron 2007, 93, 9267-9331.

[28] L. F. Tietze, Chem. Rev. 1996, 96, 115-136.

[29] H. Pellissier, Adv. Synth. Catal. 2012, 354, 237-294.

[30] B. B. Touré, D. G. Hall, Chem. Rev. 2009, 109, 4439-4486.

[31] L. Wu, Y.-M. He, Q.-H. Fan, Adv. Synth. Catal. 2011, 353, 2915-2919.

[32] S. Nishimura, Handbook of Heterogeneous Catalytic Hydrogenation for Organic Synthesis, Wiley-VCH, New York, 2001.

[33] H. Suzuki, H. Gyoutoku, H. Yokoo, M. Shinba, Y. Sato, H. Yamada, Y. Murakami, Synlett 2000, 1196-1198.

[34] A. Reissert, Ber. 1897, 30, 1030-1053.

[35] W. S. Knowles, Adv. Synth. Catal. 2003, 345, 3-13.

[36] R. Noyori, Adv. Synth. Catal. 2003, 345, 15-32.

[37] Á. Zsigmond, I. Balatoni, F. Notheisz, Zs. Herseczky, J. Bakos, Catal. Lett. 2005, 101, 195199. 
[38] S. Akahori, S. Sakurai, Y. Izumi, Y. Fujii, Nature 1956, 178, 323-328.

[39] Y. Izumi, M. Imaida, H. Fukawa, S. Akabori, Bull. Chem. Soc. Jpn. 1963, 36, 155-160.

[40] T. Sugimura, S. Nakagawa, A. Tai, Bull. Chem. Soc. Jpn. 2002, 75, 355-363.

[41] T. Osawa, T. Harada, O. Takayasu, Curr. Org. Chem. 2006, 10, 1513-1531.

[42] M. Studer, H. U. Blaser, Adv. Synth. Catal. 2003, 345, 45-65.

[43] M. Bartók, Curr. Org. Chem. 2006, 10, 1533-1567.

[44] T. Mallat, E. Orglmeister, A. Baiker, Chem. Rev. 2007, 107, 4863-4890.

[45] J. L. Margitfalvi, E. Tálas, "Asymmetric hydrogenation of activated ketones" in Catalysis (Eds.: J. J. Spivey, K. M. Dooley), 2010, 22, 144-278.

[46] Y. Orito, S. Imai, S. Niwa, Nippon Kagaku Kaishi 1979, 1118-1120.

[47] Y. Orito, S. Imai, S. Niwa, Nippon Kagaku Kaishi 1980, 670-674.

[48] J. R. G. Perez, J. Malthete, J. Jacques, C. R. Acad. Sci. Paris, 1985, Ser II, 300, 169-172.

[49] Y. Nitta, J. Watanabe, T Okuyama, T Sugimura, J. Catal. 2005, 236, 164-167.

[50] Gy. Szőllősi, Magyar Kém. Foly. 2007, 113, 145-152.

[51] Gy. Szőllősi, B. Hermán, K. Felföldi, F. Fülöp, M. Bartók, Adv. Synth. Catal. 2008, 350, 2804-2814.

[52] Zs. Makra, Gy. Szőllősi, M. Bartók, Catal. Today, 2012, 181, 56-61.

[53] W.-R. Huck, T. Mallat, A. Baiker, New J. Chem. 2002, 26, 6-8.

[54] H.-U. Blaser, H. Hönig, M. Studer, C. Wedemeyer-Exl, J. Mol. Catal A: Chem. 1999, 139, 253-257.

[55] Gy.Szöllősi, I. Kun, M. Bartók, Chirality 2001, 13, 619-624.

[56] Gy. Szőllősi, K. Szőri, M. Bartók, J. Catal. 2008, 256, 349-352.

[57] Cinchona Alkaloids in Synthesis and Catalysis: Ligands, Immobilization and Organocatalysis, (Ed.: C. E. Song), Wiley-VCH, Weinheim, 2009.

[58] H. U. Blaser, U. Siegrist, H. Steiner, M. Studer, "Aromatic nitrocompounds" in Fine Chemicals through Heterogeneous Catalysis (Eds.: R. A. Sheldon, H. van Bekkum), Wiley$V C H$, Weinheim, 2001, chap. 8.5., 389-406.

[59] B. Leipzig, Z. Elektrochemie 1898, 4, 506-514.

[60] M. Freifelder, Practical Catalytic Hydrogenation, Wiley-Interscience, New York, 1971.

[61] H.-U. Blaser H. Steiner, M. Studer, ChemCatChem 2009, 1, 210-221.

[62] D. A. Dudley, J. J. Edmunds, (Warner-Lambert Co) U.S. Patent 2005; 855,726 B1.

[63] Y. Luo, F. Tao, Y. Liu, B. Li, G. Zhang, Can. J. Chem. 2006, 84, 1620-1625.

[64] Gy. Szőllösi, M. Bartók, Arkivoc 2012, v, 16-27.

[65] G. Jas, A. Kirschning, Chem. Eur. J. 2003, 9, 5708-5723.

[66] A. Kirschning, H. Monenschein, R. Wittenberg, Angew. Chem. Int. Ed. 2001, 40, 650-679.

[67] S. V. Ley, I. R. Baxendale, R. N. Bream, P. S. Jackson, A. G. Leach, D. A. Longbottom, M. Nesi, J. S. Scott, R. I. Storer, S. J. Taylor, J. Chem. Soc. Perkin Trans. 1, 2000, 3815-4195.

[68] D. H. Drewry, D. M. Coe, S. Poon, Med. Res. Rev. 1999, 19, 97-148.

[69] P. A. Meheux, A. Ibbotson, P. B. Wells, J. Catal. 1991, 128, 387.

[70] N. Kunzle, R. Hess, T. Mallat, A. Baiker, J. Catal. 1999, 186, 239-241.

[71] B. Hermán, Gy. Szöllősi, F. Fülöp, M. Bartók, Appl. Catal. A: Gen. 2007, 331, 39-43.

[72] N. Kunzle, J. W. Soler, T. Mallat, A. Baiker, J. Catal. 2002, 210, 466-470.

[73] B. P. Mason; K. E. Price; J. L. Steinbacher; , A. R. Bogdan; D. T. McQuade, Chem. Rev. 2007, 107, 2300-2318.

[74] Noël, T.Buchwald, S. L. Chem. Soc. Rev. 2011, 40, 5010-5029.

[75] Anderson, N. G. Org. Process Res. Dev. 2012, 16, 852-869.

[76] Wiles, C.;Watts, P. Green Chem. 2014, 16, 55-62.

[77] R. Jones, L. Gödörházy, D. Szalay, L. Ürge, F. Darvas, QSAR Comb. Sci. 2005, 4, 722-727.

[78] K. R.Saaby, K. R. Knudsen, M. Ladlow, S. V. Ley, Chem. Commun. 2005, 23, 2909-2911.

[79] B. Desai, O. C. Kappe, J. Combi. Chem. 2005, 7, 641-643.

[80] Gy. Szöllősi, B. Hermán, F. Fülöp, M. Bartók, React. Kinet. Catal. Lett. 2006, 88, 391-398.

[81] L. F. Tietze, U. Beifuss, Angew. Chem. Int. Ed. 1993, 32, 131-163.

[82] R. J. Robinson, Chem. Soc. Trans. 1917, 111, 762-768.

[83] H. Pellissier, Tetrahedron 2006, 62, 1619-1665. 
[84] C. J. Chapman, C. G. Frost, Synthesis 2007, 1, 1-21.

[85] A. Padwa, S. K. Bur, Tetrahedron 2007, 63, 5341-5378.

[86] K. C. Nicolaou, D. J. Edmonds, P. G. Bulger, Angew. Chem. Int. Ed. 2006, 45, 7134-7186.

[87] C. Grondal, M. Jeanty, D. Enders, Nat. Chem. 2010, 2, 167-178.

[88] Gy. Szőllősi, Magyar Kém. Foly. 2014, 120, 77-82.

[89] B. M. Choudary, N. S. Chowdari, S. Madhi, M. L. Kantam, Angew. Chem. Int. Ed. 2001, 40, 4620-4623.

[90] B. M. Choudary, N. S. Chowdari, K. Jyothi, N. S. Kumar, M. L. Kantam, Chem. Commun. 2002, 586-587.

[91] S. Yang, J. He, Chem. Commun. 2012, 48, 10349-10351.

[92] K. Akagawa, R. Umezawa, K. Kudo, Beilstein J. Org. Chem. 2012, 8, 1333-1337.

[93] X. Jiang, H. Zhu, X. Shi, Y. Zhong, Y. Li, R. Wang, Adv. Synth. Catal. 2013, 355, 308-314.

[94] L. Deiana, L. Ghisu, S. Afewerki, O. Verho, E. V. Johnston, N. Hedin, Z. Bacsik, A. Córdova, Adv. Synth. Catal. 2014, 356, 2485-2492.

[95] J. Yadav, G. R. Stanton, X. Fan, J. R. Robinson, E. J. Schelter, P. J. Walsh, M. A. Pericas, Chem. Eur. J. 2014, 20, 7122-7127.

[96] Z. An, Y. Guo, L. Zhao, Z. Li, J. He, ACS Catal. 2014, 4, 2566-2576.

[97] K. Felföldi, K. Szöri, M. Bartók, Appl. Catal. A: Gen. 2003, 351, 457-460.

[98] J. Poulin, C. M. Grisé-Bard, L. Barriault, Chem. Soc. Rev. 2009, 38, 3092-3101.

[99] A.-N. Alba, X. Companyo, M. Viciano, R. Rios, Curr. Org. Chem. 2009, 13, 1432-1474.

[100] J. Barluenga, F. Rodríguez, F. J. Fañanás, Chem. Asian J. 2009, 4, 1036-1048.

[101] H. Pellissier, Chem. Rev. 2013, 113, 442-524.

[102] E. Alza, S. Sayalero, X. C. Cambeiro, R. Martín-Rapún, P. O. Miranda, M. A. Pericás, Synlett 2011, 464-468.

[103] A. Baiker, J. Mol. Catal. A: Chem. 1997, 115, 473-493.

[104] A. Baiker, J. Mol. Catal. A: Chem. 2000, 163, 205-220.

[105] C. Exner, A. Pfaltz, M. Studer, H.-U. Blaser, Adv. Synth. Catal. 2003, 345, 1253-1260.

[106] D. R. Boyd, N. D. Sharma, J. G. Carroll, J. F. Malone,D. G. Mackerracher, C. C. R. Allen, Chem. Commun. 1998, 683-684.

[107] For further details see: http://thalesnano.com/h-cube (2016. 03. 03.).

[108] K. C. Nicolaou, A. A. Estrada, G. C. Freestone, S. H. Lee, X. Alvarez-Mico, Tetrahedron 2007, 63, 6088-6114.

[109] B. Török, K. Balázsik, Gy. Szőllősi, K. Felföldi, M. Bartók, Chirality 1999, 11, 470-474.

[110] M. von Arx, T. Mallat and A. Baiker, J. Catal. 2000, 193, 161-164.

[111] K. Balázsik, K. Szőri, Gy. Szőllősi, M. Bartók, Chem. Commun. 2011, 47, 1551-1552.

[112] K. Balázsik, K. Szőri, Gy. Szőllősi, M. Bartók, Catal. Commun. 2011, 12, 1410-1414.

[113] U. K. Singh, R. N. Landau, Y. Sun, C. LeBlond, D. G. Blackmond, S. K. Tanielyan and R. L. Augustine, J. Catal. 1995, 154, 91-97.

[114] M. Casagrande, S. Franceschini, M. Lenarda, O. Piccolo, A. Vaccari, J. Mol. Catal. A: Chem. 2006, 246, 263-267.

[115] D. Yu. Murzin, P. Mäki-Arvela, E. Toukoniitty, T. Salmi, Catal. Rev.: Sci. Eng. 2005, 47, 175-256.

[116] R. Blout, D. C. Silverman, J. Am. Chem. Soc., 1944, 66, 1442-1443.

[117] S. Santiago-Pedro, V. Tamayo-Galván, T. Viveros-García, Catal. Today, 2013, 213, 101-108.

[118] Gy. Szőllősi, P. Forgó, M. Bartók, Chirality 2003, 15, S82-S89.

[119] Blaser, M. Studer, Acc. Chem. Res. 2007, 40, 1348-1356.

[120] F. Zaera, J. Phys. Chem. C 2008, 112, 16196-16203.

[121] K. Szőri, K. Felföldi, M. Bartók, Appl. Catal. A: Gen. 2003, 251, 457-460.

[122] D. Ferri, T. Bürgi, J. Am. Chem. Soc. 2001, 123, 12074-12084.

[123] Ferri, T. Bürgi, A. Baiker, J. Catal., 2002, 210, 160-170.

[124] M. Bartók, M. Sutyinszki, K. Balázsik, Gy. Szőllősi, Catal. Lett., 2005, 100, 161-167.

[125] Gy. Szőllősi, Sz. Cserényi, F. Fülöp, M. Bartók, J. Catal. 2008, 260, 245-253.

[126] Gy. Szőllősi, Sz. Cserényi, M. Bartók, Catal. Lett. 2010, 134, 264-269.

[127] D. Cantillo, C. O. Kappe, ChemCatChem 2014, 6, 3286-3305.

[128] V. Morawsky, U. Prüße, L. Witte, K-D. Vorlop, Catal. Commun. 2000, 1, 15-20. 
Appendix 